
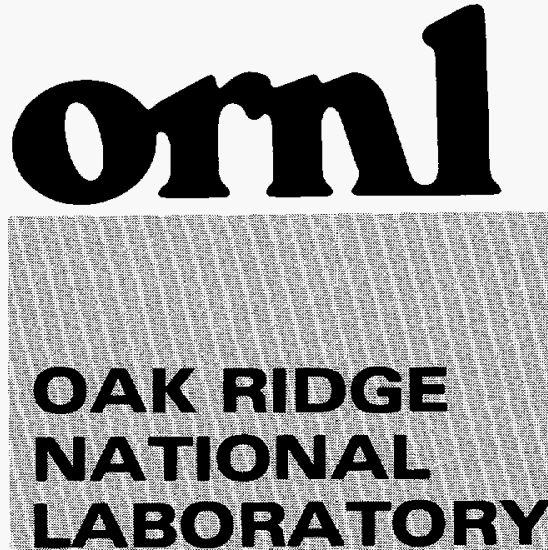

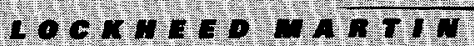



RECEIVED

\section{SEP 291997 \\ OSTI}

\author{
Computer Science and Mathematics Division \\ Mathematical Sciences Section
}

RESULTS OF THE ANALYSIS OF

THE BLOOD LYMPHOCYTE PROLIFERATION TEST DATA

FROM THE NATIONAL JEWISH CENTER

\author{
E. L. Frome ${ }^{*}$ \\ L.S. Newman' \\ M. M. Mroz'
}
- Mathematical Sciences Section
Oak Ridge National Laboratory
Oak Ridge, Tennessee 37831-0117
- National Jewish Center For Immunology and Respiratory Medicine
Denver, Colorado

Date Published: March 1997

Research was supported by the Offices of Occupational Medicine,

Environment, Safety and Health, U.S. Department of Energy

Prepared by the

Oak Ridge National Laboratory

Oak Ridge, Tennessee 37831

managed by

Lockheed Martin Energy Research Corp.

for the

U.S. DEPARTMENT OF ENERGY

under Contract No. DE-AC05-96OR22464

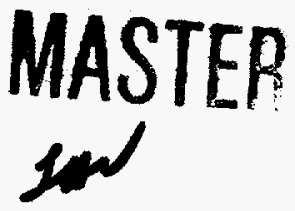

IS UNLWHED 
This report has been reproduced directly from the best available copy.

Available to DOE and DOE contractors from the Office of Scientific and Technical Information, P. O. Box 62, Oak Ridge, TN 37831; prices available from (615) 576-8401, FTS 626-8401.

Available to the public from the National Technical Information Service, U.S. Department of Commerce, 5285 Port Royal Rd., Springfield, VA 22161.

This report was prepared as an account of work sponsored by an agency of the United States Government. Neither the United States Government nor any agency thereof, nor any of their employees, makes any warranty, express or implied, or assumes any legal liability or responsibility for the accuracy, completeness, or usefulness of any information, apparatus, product, or process disclosed, or represents that its use would not infringe privately owned rights. Reference herein to any specific commercial product, process, or service by trade name, trademark, manufacturer, or otherwise, does not necessarily constitute or imply its endorsement, recommendation, or favoring by the United States Government or any agency thereof. The views and opinions of authors expressed herein do not necessarily state or reflect those of the United States Government or any agency thereof. 


\section{DISCLAIMER}

Portions of this document may be illegible electronic image products. Images are produced from the best available original document. 
Computer Science and Mathematics Division

Mathematical Sciences Section

\title{
RESULTS OF THE ANALYSIS OF \\ THE BLOOD LYMPHOCYTE PROLIFERATION TEST DATA \\ FROM THE NATIONAL JEWISH CENTER
}

\author{
E. L. Frome * \\ L.S. Newman \\ M. M. Mroz ${ }^{\dagger}$
}

- Mathematical Sciences Section

Oak Ridge National Laboratory

Oak Ridge, Tennessee 37831-0117

+ National Jewish Center For Immunology and Respiratory Medicine

Denver, Colorado

Date Published: March 1997

Research was supported by the Offices of Occupational Medicine, Environment, Safety and Health, U. S. Department of Energy

Prepared by the Oak Ridge National Laboratory

Oak Ridge, Tennessee 37831 managed by Lockheed Martin Energy Research Corp.

for the

U.S. DEPARTMENT OF ENERGY

under Contract No. DE-AC05-96OR22464 
- 


\section{Contents}

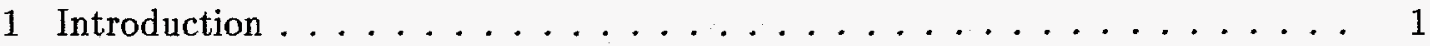

1.1 Description of Data From National Jewish Center . . . . . . . . . . 2

2 Estimation of SIs Using Least Absolute Values Method . . . . . . . . . . . . . 3

2.1 Regression Model for the LPT Data . . . . . . . . . . . . . . . . 3

2.2 Least Absolute Value Regression on $\log (\mathrm{y}) \ldots \ldots \ldots$

3 Identification of LPTs With Large SIs . . . . . . . . . . . . . . . 5

3.1 Method 1- Using Distribution of Maximum SI From Nonexposed Controls and/or Historical Population of Beryllium Exposed Workers . . . . 5

3.2 Method 1A- Using Distribution of Second Largest SI From Nonexposed Controls and/or Historical Population of Beryllium Exposed Workers . . 6

3.3 Method 2- Using The Empirical Distribution of $\log (\mathrm{SI}) \mathrm{s}$ For Each Day and Each Beryllium Concentration . . . . . . . . . . . 6

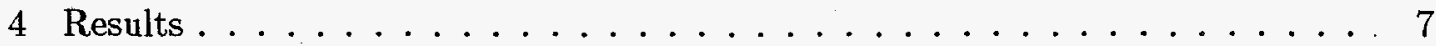

4.1 Descriptive Statistics for Control Wells . . . . . . . . . . . . . 7

4.2 Graphical Summaries for SIs For Beryllium Exposed Workers and Non-

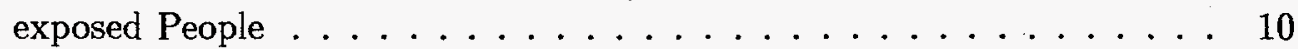

4.3 Resistant Estimates of the Coefficient of Variation $(\tilde{\phi}) \ldots \ldots \ldots$

4.4 Identification Of LPTs With Large SIs . . . . . . . . . . . . 20

5 Comparison of The Three Methods . . . . . . . . . . . . . . . 24

5.1 Classification of Unacceptable LPTs . . . . . . . . . . . . . 25

5.1.1 Method 1 Results Based On Maximum SI . . . . . . . . . . 26

5.1.2 Method 1A Results Based On Second Largest SI . . . . . . . . 26

5.1.3 Method 2 Results Based On Each Day/Concentration . . . . . 26

6 Criteria For Unacceptable LPTs . . . . . . . . . . . . . . . 28

6.1 Criteria To Determine If Internal Variability Is Too High $\ldots \ldots$. . . . 28

6.1 .1 Empirical Approach . . . . . . . . . . . . 29



6.1 .3 Mathematical Analysis . . . . . . . . . . . . 29

6.1.4 Simulation Based Approach ............. 30

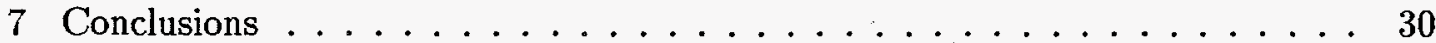

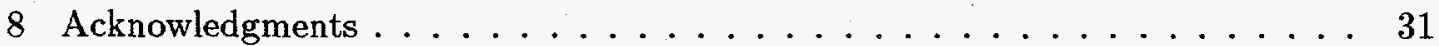



A Detailed Report For LPT Data . . . . . . . . . . . . 33 


\section{List of Tables}

1 Abnormal LPTs Using Method 1 For Sample of Beryllium Exposed Workers . . . . . . . . . . . . . . . . . . . 21

2 Abnormal LPTs Using Method 1A For Sample of Beryllium Exposed Workers . . . . . . . . . . . . . . . . . . 22

3 Abnormal LPTs Using Method 2 For Sample of Beryllium Exposed

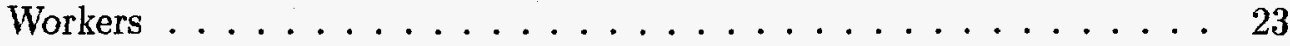

4 Beryllium Exposed Workers Classified as Abnormal by at Least One Method $^{a} \ldots \ldots \ldots \ldots \ldots \ldots 24$

5 Summary For NJC Unacceptable LPTs . . . . . . . . . . . . . 25

6 Retest Summary Results For Method 1 . . . . . . . . . . . . 27

7 Summary RETEST Results For Method 1A . . . . . . . . . . 27

8 Retest Summary Results For Method 2 . . . . . . . . . . . 27 



\section{List of Figures}

1 Day 5 Control Wells: Moment and Resistant Estimates-Linear Scale. . 8

2 Nonexposed and Beryllium Exposed Workers-Sample. Log-Log Plots For Day 5 and Day 7 Control Wells. . . . . . . . . . . . 9

3 All Data Day 5 and Day 7 Control Wells- Log-Log Plots . . . . . . 11

4 Boxplots of SIs for Sample of Beryllium Exposed Workers and Controls 12

5 Normal Probability Plots of $\operatorname{LAV} \log (\mathrm{SI}) \mathrm{s} \ldots \ldots \ldots \ldots \ldots$

6 Normal Probability Plots For Nonexposed . . . . . . . . . . . . 15

$7 \quad$ SIs For Nonexposed (Controls) and Beryllium Exposed Workers . . . . . 16

8 Resistant Estimates of $\tilde{\phi}(\mathrm{CV}) \ldots \ldots \ldots \ldots \ldots \ldots$

$9 \quad$ Normal Probability Plots For $\log (\tilde{\phi}) \ldots \ldots \ldots \ldots \ldots$

10 Distributions of Maximum of $\log (\mathrm{SI})$ For NJC Data Sets . . . . . . 19 


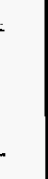




\title{
RESULTS OF THE ANALYSIS OF THE BLOOD LYMPHOCYTE PROLIFERATION TEST DATA FROM THE NATIONAL JEWISH CENTER
}

\author{
E. L. Frome
}

L.S. Newman

M. M. Mroz

\begin{abstract}
A new approach to the analysis of the blood beryllium lymphocyte proliferation test (LPT) was presented to the Committee to Accredit Beryllium Sensitization Testing-Beryllium Industry Scientific Advisory Committee in April, 1994. Two new outlier resistant methods were proposed for the analysis of the blood LPT and compared with the approach then in use by most labs. The method based on a least absolute values (LAV) analysis of the log of the well counts was recommended for routine use. It was considered important to "field test" the method on a new data base from another laboratory, since results were obtained using data from a single laboratory-Oak Ridge Institute for Science and Education (ORISE).

The National Jewish Center (NJC) agreed to provide data (similar to that from ORISE in ORNL-6818) from a study that was underway at that time. Three groups of LPT data are considered; i) a sample of 168 beryllium exposed (BE) workers and 20 nonexposed (NE) persons; ii) 25 unacceptable LPTs, and iii) 32 abnormal LPTs for individuals known to have chronic beryllium disease (CBD). The LAV method described in ORNL-6818 was applied to each LPT. Graphical and numerical summaries similar to those presented for the ORISE data are given. Three methods were used to identify abnormal LPTs. All three methods correctly identified the 32 known CBD cases as abnormal. Results of applying the three methods to the BE-sample and Unacceptable data sets are presented, and results for each of the three methods for the 20 Unacceptable LPTs and retest results are given.

These results support the earlier recommendation that the LAV method is a simple and effective method for routine analysis of the blood beryllium LPT that is not effected by outliers.
\end{abstract}




\section{Introduction}

On April 22, 1994 a new approach to the analysis of the blood beryllium lymphocyte proliferation test (LPT) ${ }^{1}$ was presented at the Committee to Accredit Beryllium Sensitization Testing-Beryllium Industry Scientific Advisory Committee meeting in Washington, D.C. The details of the method are described ${ }^{2}$ by Frome et al in a research report (ORNL-6818) [4] and were presented on November 8, 1994 at the Conference on Beryllium Related Diseases [5]. At the meeting there was general satisfaction with the proposed methods, but it was considered important to "field test" the method on a new data base from another laboratory-results in ORNL-6818 were obtained using data from the Oak Ridge Institute for Science and Education (ORISE) laboratory. The National Jewish Center (NJC) agreed to provide data similar to that in ORNL-6818 from a study that was underway at that time.

In ORNL-6818 two outlier resistant methods were proposed for the estimation of the stimulation index (SI), which is the ratio of the response of beryllium stimulated cells to control cells. These outlier resistant methods were compared with the approach then in use by most labs. The method based on a least absolute values (LAV) analysis (Section 2.2) of the $\log$ of the well counts was recommended for routine use. In this report all of the results are based on the LAV method. All LPTs showed an adequate response to concanavalin- $\mathrm{A}$ (ConA) and phytohemagglutinin (PHA) and those with obvious "laboratory error" (i.e. many wells with no response above background) have been eliminated.

\footnotetext{
${ }^{1}$ Abbreviations used: AB,abnormal; Be,beryllium; BE,beryllium exposed; CBD, chronic beryllium disease; ConA,concanavalin-A; CV., coefficient of variation; df,degrees of freedom; LAV,least absolute values; LPT,lymphocyte proliferation test; NE,nonexposed; NJC,National Jewish Center; ORISE,Oak Ridge Institute for Science and Education; ORNL, Oak Ridge National Laboratory; PHA,phytohemagglutinin; SI,stimulation index; UN, unacceptable;

${ }^{2}$ On the Internet see URL: http://www.epm.ornl.gov/ frome/BeLPT/index.html
} 


\subsection{Description of Data From National Jewish Center}

Three groups of LPT data are considered:

- LPTs for a sample of 168 beryllium exposed (BE) workers and 20 nonexposed (NE) persons.

- 25 unacceptable (UN) LPTs, and

- 32 abnormal (AB) LPT data sets.

The sample data consists of the first 168 persons whose blood arrived at NJC for beryllium testing as part of a recent study and are considered to be representative of the study cohort. One LPT from the beryllium exposed workers was removed because of laboratory error (eight of twelve control wells showed background counts). The nonexposed LPT data are from 20 people who have no known beryllium exposure or respiratory disorders. These $20 \mathrm{LPTs}$ were performed by a single NJC technician.

The unacceptable data are from 25 patients who have "high variability" in their beryllium test results or control cells. Data are flagged as unacceptable for any of the following reasons:

- three or more of the six beryllium stimulated groups are excluded due to high variation

- more than five control well data values are excluded due to high variation,

- ConA and PHA SIs are low (indicating low cell viability), or

- cell control counts are judged to be too high or too low (indicating possible contamination, failure to pulse, or other laboratory error).

High variation is defined in several ways. For beryllium stimulated quadruplicates (groups of four at a particular beryllium concentration), values are rank ordered and the coefficient of variation $(\mathrm{CV})$ is calculated. If the $\mathrm{CV}$ is greater than $30 \%$, the value farthest from the mean is dropped and the $\mathrm{CV}$ is recalculated. If the $\mathrm{CV}$ for the remaining three values is still above $30 \%$, the group is excluded. Three or more excluded groups is considered high variation. High variation for cell control groups is 
the same as for beryllium stimulated groups with one exception. It is defined as more than five control well counts excluded from the group without achieving an acceptable CV.

The abnormal data are from 32 patients who have clinically confirmed beryllium disease or beryllium sensitivity. The data are considered abnormal if two or more SIs exceed the technician's cut-off value. The cut-off value is two standard deviations above the mean peak SI for nonexposed people.

\section{Estimation of SIs Using Least Absolute Values Method}

Results in this report are based on the LAV method described in detail in ORNL-6818. The main results are summarized here.

\subsection{Regression Model for the LPT Data}

Let $y_{j k}$ denote the well count for the $k^{\text {th }}$ replicate of the $j^{\text {th }}$ set of culture conditions. The expected count in each well can be represented by a log-linear regression function:

$$
E\left(y_{j k}\right)=\lambda_{j}=\exp \left(\boldsymbol{X}_{\boldsymbol{j}} \boldsymbol{\beta}\right)
$$

where $j=1, \ldots, 10$ and $k=1, \ldots, 12$ for the controls and $k=1,2,3,4$ for the beryllium stimulated cells and the positive controls. In (1), $\boldsymbol{X}_{\boldsymbol{j}}$ is a row vector of indicator variables and $\boldsymbol{\beta}$ is the vector of regression parameters (see below). It is further assumed that the variance of the well counts is proportional to the square of the expected count:

$$
\operatorname{Var}\left(y_{j k}\right)=\left(\phi \lambda_{j}\right)^{2}
$$

Equations 1 and 2 together are referred to as a generalized linear model with constant coefficient of variation $\phi$ (see ORNL-6818 for more details)

\subsection{Least Absolute Value Regression on $\log (\mathbf{y})$}

The first step in this approach is to take the log of the counts since this is the variancestabilizing transformation and leads to a linear model in say $z_{j k}=\log \left(y_{j k}\right)$, i.e.

$$
E\left(z_{j k}\right)=\boldsymbol{X}_{\boldsymbol{j}} \boldsymbol{\beta}-\phi^{2} / 2 \text { and } \operatorname{Var}\left(z_{j k}\right) \simeq \phi^{2}
$$


In this report all logs are natural (base e) logarithms. If outliers are not present, applying ordinary least squares to the transformed data will yield consistent estimates for the $\log (\mathrm{SI})$ parameters [7]. The effect of outliers is minimized by using least absolute values (or some other robust method) on the $z_{j k}$. Least absolute value regression-also known as $L_{1}$ norm, least absolute deviations and minimum sum of absolute errors-is well known to be resistant to outliers and is an important particular case of a general class of robust methods known as M-estimators [10, 9]. In general, LAV regression requires special computational resources to calculate parameter estimates [1]. In this situation, however, it is only necessary to find the median of the log of the well counts for each set of design conditions and then subtract the control median for each harvest day from the beryllium stimulated medians (see Appendices ORNL-6818). Let $\tilde{z}_{j}$ denote the median for the $j^{\text {th }}$ beryllium concentration and $\tilde{z}_{o}$ denote the median of the log well counts for beryllium stimulated cells and the corresponding control wells. The LAV estimate of the $j^{\text {th }} \log (\mathrm{SI}), \tilde{\beta}_{j}$, is

$$
\tilde{\beta}_{j}=\tilde{z}_{j}-\tilde{z}_{o}
$$

A resistant estimate of the coefficient of variation $(\phi)$ can then be obtained as

$$
\tilde{\phi}=C \times \operatorname{median}\left\{\left|z_{j k}-\tilde{z}_{j}\right|\right\}
$$

where $C=1.48 \times \sqrt{n /(n-p)}, n=$ number of wells, and $p=$ the number of medians. On the $\log$ scale $\phi$ corresponds to the standard deviation of the log counts. For the overall pooled estimate $n=48$ and $p=8$ in this report. The value of $C$ is chosen to make the estimate consistent for the standard deviation for a Gaussian error model and for consistency with the usual least squares results in which the estimated variance is multiplied by the correction factor $n /(n-p)$ - see [6] and S-PLUS function mad in [12]. Alternative approaches to estimating $\phi$ have been discussed in the context of LAV regression (see e.g., $[11,9]$ ) and there is no consensus as to the best approach. In addition to the fact that this parameter is of direct interest in this situation, it is also needed to obtain an estimate of the parameter covariance matrix

$$
w^{2}\left(\boldsymbol{X}^{\prime} \boldsymbol{X}\right)^{-1}
$$


where $w^{2}=[2 f(0)]^{-2}$ is the asymptotic variance of the sample median [2]. Following the approach of [8] we assume that the underlying error distribution is Gaussian in the center and use $\tilde{w}=\sqrt{\pi / 2} \tilde{\phi}_{L}$ to obtain an estimate of the standard deviation of the $\log$ of the stimulation indices. The appropriate diagonal term from $\left(X^{\prime} X\right)^{-1}$ is $4 / 12$, and consequently the estimated standard deviation of $\log (\mathrm{SI})$ is $1.25 \tilde{\phi}_{L}(0.58)=0.72 \tilde{\phi}_{L}$.

\section{Identification of LPTs With Large SIs}

This section describes three approaches to the the problem of identification of an "abnormal" LPT. Each of these methods uses the LAV estimates $\tilde{\beta}_{j}, j=1, \ldots, 6$, of the $\log (\mathrm{SI}) \mathrm{s}$ and resistant estimates of $\phi$. Note that $\tilde{\beta}_{j}$ is a statistical shorthand for the LAV estimate of the $j^{\text {th }} \log (\mathrm{SI})$.

\subsection{Method 1- Using Distribution of Maximum SI From Nonexposed Con- trols and/or Historical Population of Beryllium Exposed Workers}

This approach parallels that currently in use for identification of LPTs with large SIs. The procedure is to use the distribution of the maximum $\log (\mathrm{SI})$ in a reference data base of LPT data sets to determine a "cut point". The reference data base could be composed of LPTs for a group of nonexposed individuals, or nonexposed plus historical data from beryllium exposed workers with no indication of beryllium sensitivity. In this report there are LPTs for 20 nonexposed individuals, and these, alone or in combination with the sample of 167 beryllium exposed workers, will serve as the reference data base. The individuals with abnormal LPTs have not been removed. The methods we use are outlier resistant and should be effective as long as the proportion of abnormal LPTs in the study population is not too large. ${ }^{3}$ An LPT is considered abnormal if at least two $\log (\mathrm{SI}) \mathrm{s}$ exceed this cut point. The steps for this procedure are as follows:

1. Find $\beta_{i}^{*}=\max \left[\tilde{\beta}_{i j}, j=1, \ldots, 6\right]$ for $i=1, \ldots, N$, where $N=$ number of LPTs in reference data base.

2. Find $M=\operatorname{median}\left[\beta_{i}^{*}, i=1, \ldots, N\right]$ and $\mathrm{S}$ the median absolute deviation (MAD) estimate of the standard deviation of the $\beta_{i}^{*}$.

\footnotetext{
${ }^{3}$ If the reference data base is restricted to $\mathrm{NE}$ individuals, then the moment estimates of location and scale could be used instead of the resistant estimates. This approach is based on the assumption that there are no beryllium sensitive individuals in the NE group.
} 
3. Then calculate $c u t=\mathrm{M}+z_{p} \mathrm{~S}$, where $z_{p}$ is the $p^{\text {th }}$ quantile of the standard normal distribution. If $p=0.975$ then $z_{p} \approx 2$.

4. An LPT is defined to be abnormal if at least two $\log (S I)$ s exceed cut.

The probability of a statistical false positive for this procedure is less than 1-p.

\subsection{Method 1A- Using Distribution of Second Largest SI From Nonexposed Controls and/or Historical Population of Beryllium Exposed Workers}

This approach is the same as Method 1 except the second largest $\log (\mathrm{SI})$ in a reference data base of LPT data sets is used to determine the "cut point". An LPT is considered abnormal if the second largest $\log (\mathrm{SI})$ exceeds this cut point. The steps for this procedure are as follows:

1. Find $\beta_{i}^{\dagger}=$ secondlargest $\left[\tilde{\beta}_{i j}, j=1, \ldots, 6\right]$ for $i=1, \ldots, N$, where $N=$ number of LPTs in reference data set.

2. Find $M=$ median $\left[\beta_{i}^{\dagger}, i=1, \ldots, N\right]$ and $\mathrm{S}$ the median absolute deviation (MAD) estimate of the standard deviation of the $\beta_{i}^{\dagger}$.

3. Then calculate $c u t=\mathrm{M}+z_{p} \mathrm{~S}$, where $z_{p}$ is the $p^{t h}$ quantile of the standard normal distribution. If $p=0.975$ then $z_{p}=1.96$.

4. An LPT is defined to be abnormal if at least two $\log (S I)$ s exceed cut.

The probability of a false positive for this procedure should be about 1-p.

\subsection{Method 2- Using The Empirical Distribution of $\log (\mathrm{SI}) \mathrm{s}$ For Each Day and Each Beryllium Concentration}

The third approach is the one proposed in Section 3.6 of ORNL-6818. It is based on the assumption that the $\log (\mathrm{SIs})$ are approximately normally distributed (see Figures 5 and 6). In this report the reference data base consists of all available LPTs in the BE-sample data set and the NE data set. In practice this data set would change during the course of a study as new data becomes available. The first step is to convert each $\log (\mathrm{SI})$ into a standardized deviate

$$
u_{i j}=\frac{\tilde{\beta}_{i j}-\tilde{\mu}_{j}}{\tilde{s}_{j}}
$$


using the values of $\tilde{\mu}_{j}$ and $\tilde{s}_{j}$ given in Table 3 . These standardized deviates can be compared with the quantiles of the standard normal distribution, i.e. $\operatorname{Pr}\left[u<z_{p}\right]=p$. If we assume that the $\log (\mathrm{SIs})$ are independent then the binomial distribution can be used to calculate an approximate probability of at least $k$ out of six "large" SIs for a given value of $z_{p}$. The probability of at least one large SI is $1-p^{6}$, and the probability of at least two is $1-\left[p^{6}+6(1-p) p^{5}\right]$.

In fact, the $\log ($ SIs) are positively correlated, so this probability should be a lower bound on the chance of finding a false positive LPT.

\section{Results}

\subsection{Descriptive Statistics for Control Wells}

An important assumption is that the standard deviation of the well counts is proportional to the mean as implied by Equation (2). Since each of the LPTs contains 12 replicate control wells on both day 5 and day 7 we can evaluate this assumption by computing location and scale estimates for the control wells for each assay on day 5 and day 7. Figure 1 (top) shows the relationship between the moment estimator of location $(\bar{y}$, the sample mean) and the moment estimator of scale ( $s$, the sample standard deviation) for the day 5 control wells. This plot also shows the resulting line when the standard deviation is regressed on the mean. The least squares equation for this line is $\hat{\sigma}=0.29 \bar{y}$, and the slope $(0.29)$ is an estimate of the coefficient of variation for day 5 . Figure 1 (bottom) is a similar plot but resistant estimates are used in place of moment estimates. Specifically, the sample median $(\tilde{y})$ replaces the sample mean, the MAD estimate $(\tilde{\sigma})$ replaces $s$, and LAV is used to regress $\tilde{\sigma}$ on $\tilde{y}$. The solution to this resistant fit is $\tilde{\sigma}=0.22 \tilde{y}$ and the slope $(0.22)$ is a resistant estimate of the coefficient of variation.

Figure 2 shows the relationship between the resistant estimates of location and scale for the day 5 control wells (top) and the day 7 control wells (bottom) on a $\log -\log$ scale. If the standard deviation is proportional to the mean (i.e. constant coefficient of variation), the $\log$-log plot should be linear with a slope of 1 . The LAV fit is $\tilde{\sigma}=0.262 \tilde{y}$ for the day 7 control wells and the solid line in Figure 2 (bottom) is $\log (\tilde{\sigma})=\log (0.262)+\log (\tilde{y})$. Comparing this fit to the resistant fit for the day 5 control wells $(\tilde{\sigma}=0.216 \tilde{y})$ reveals that the results on both days are quite similar. The main 

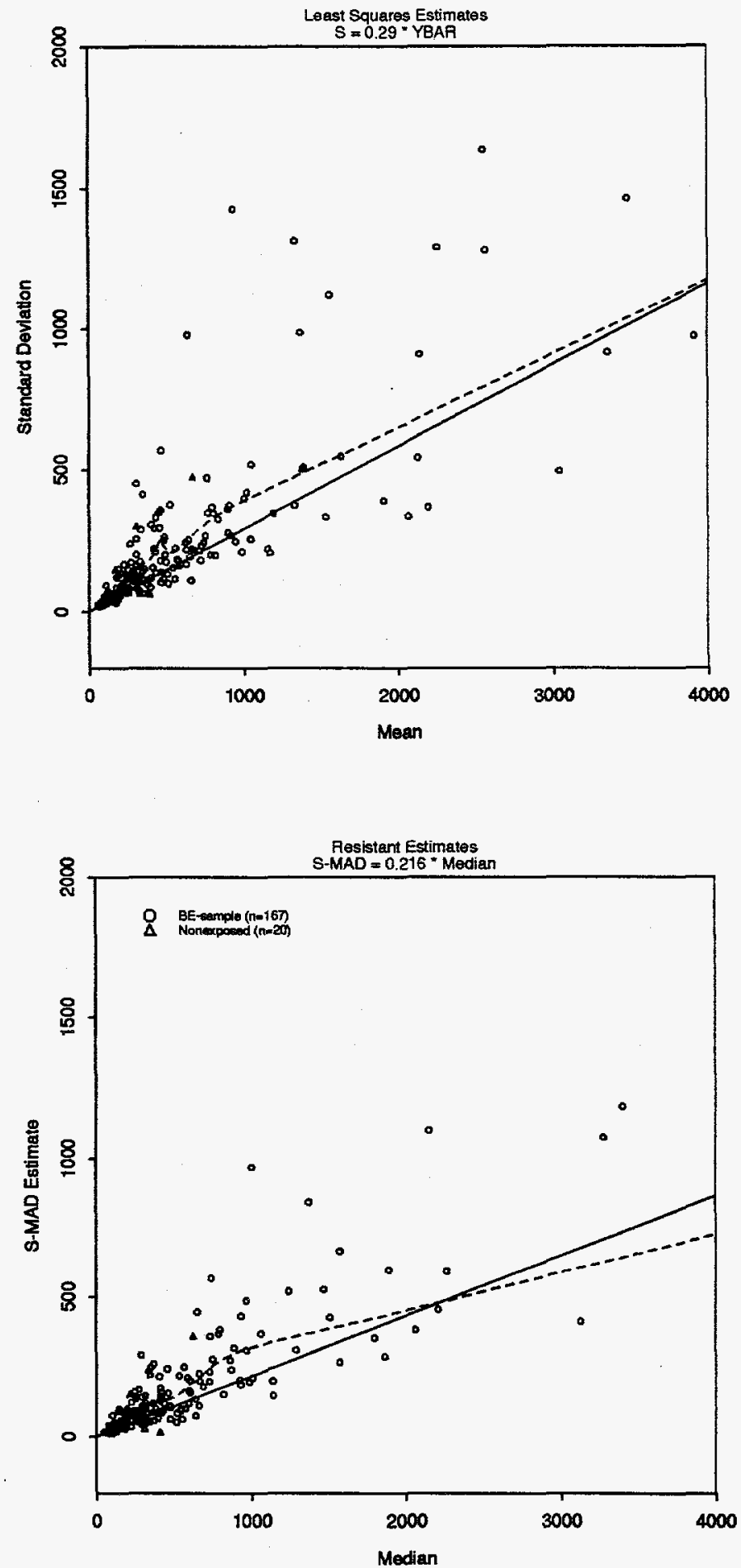

Figure 1: (Top) Relationship between the mean, $\bar{y}$, and the standard deviation, $\hat{\sigma}$, for day 5 control wells. The solid line is the ordinary least squares fit, $\hat{\sigma}=0.29 \bar{y}$. (Bottom) Relationship between the Median, $\tilde{y}$, and the MAD estimate, $\tilde{\sigma}$. The $\mathrm{L}_{1}$ solution, the solid line, is $\tilde{\sigma}=0.216 \tilde{y}$. The dashed lines are the result of applying scatterplot smoothers to the data. 

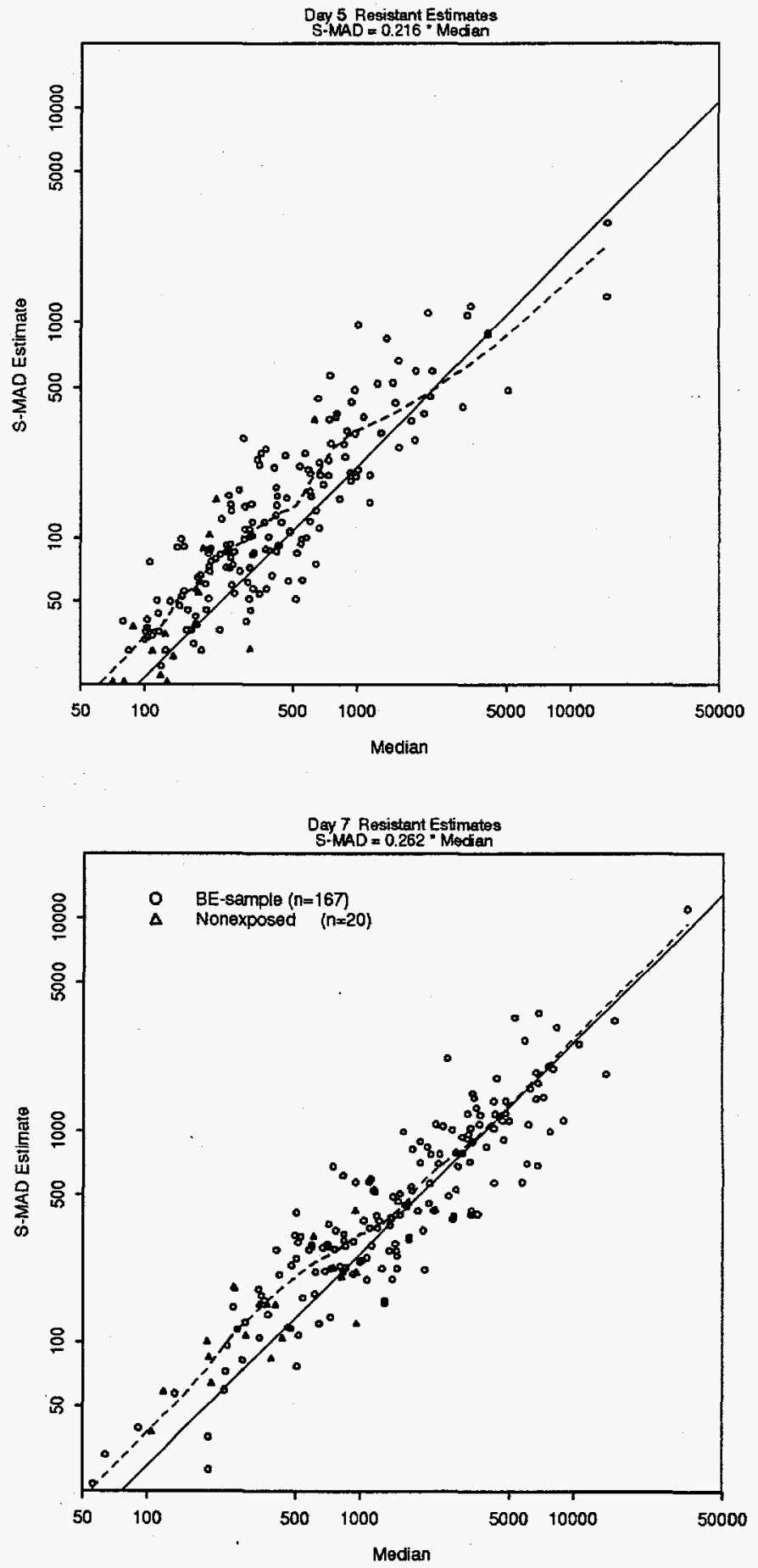

Figure 2: Results for Nonexposed and Beryllium Exposed Workers-Sample. Relationship between the Median, $\tilde{y}$, and the MAD estimate, $\tilde{\sigma}$ of the standard deviation for the control wells on harvest day 5 (top) and harvest day 7 (bottom). The dashed lines are the result of applying scatterplot smoothers to the data. Since results are shown on $\log -\log$ scale the slope of the line is 1 . 
difference in the day 5 and day 7 results is that the day 7 results are shifted to the right since the control well counts are generally higher on day 7 than those on day 5 . The median of the $\tilde{y}$ s on day 5 is 378 compared with 1552 for day 7 . These results are consistent with the laboratory observation that day 7 results are generally higher and show greater variability than well counts on day 5 . They also support the regression model assumption discussed in Section 2.1 that the variance of the well counts is proportional to the square of the expected counts.

Figure 3 is identical to Figure 2 except the results for Abnormal and Unacceptable LPTs have been included.

\subsection{Graphical Summaries for SIs For Beryllium Exposed Workers and Non- exposed People}

Figure 4 shows the SIs for the sample of beryllium exposed (BE) workers and nonexposed (NE) controls (compare with Fig. 4 for the ORISE-AC Data in Frome et al. [5]). The vertical scale on the right hand side of the plots is in SI units. The SIs for both the NE controls and the beryllium exposed workers decrease as the beryllium concentration in the test wells increases. This may be due to a toxic effect of high beryllium concentration that results in "cell killing". There is considerably more variability in the $\log (\mathrm{SI})$ s for the BE LPTs than for the NE LPTs at each concentration on both day 5 and day 7.

Figure 5 shows normal (Gaussian) probability plots for the combined $\mathrm{BE}$ and $\mathrm{NE}$ SIs for each of the three beryllium concentrations on day 5 and day 7 . In each of the six plots, the data (ordered values of the $\log (\mathrm{SIs})$ ) are shown on the vertical scale on the left, and the quantiles of the standard normal distribution are shown on the horizontal scale. A detailed account of the construction and interpretation of normal probability plots is provided by Chambers et .al [3]. In this situation statistical theory indicates that the $\log$ (SIs) should be approximately normally distributed, and the large sample standard deviation should be about 0.28 if the coefficient of variation is 0.4 . If the relation between the empirical quantiles (on the vertical axis) and theoretical quantiles (on the horizontal axis) is linear, this indicates that the distribution is Gaussian. Each plot includes the median (labeled $M$ ) and a resistant estimate of the standard deviation (labeled S) for the $\log$ SIs. The solid line in each plot shows the relation that is 

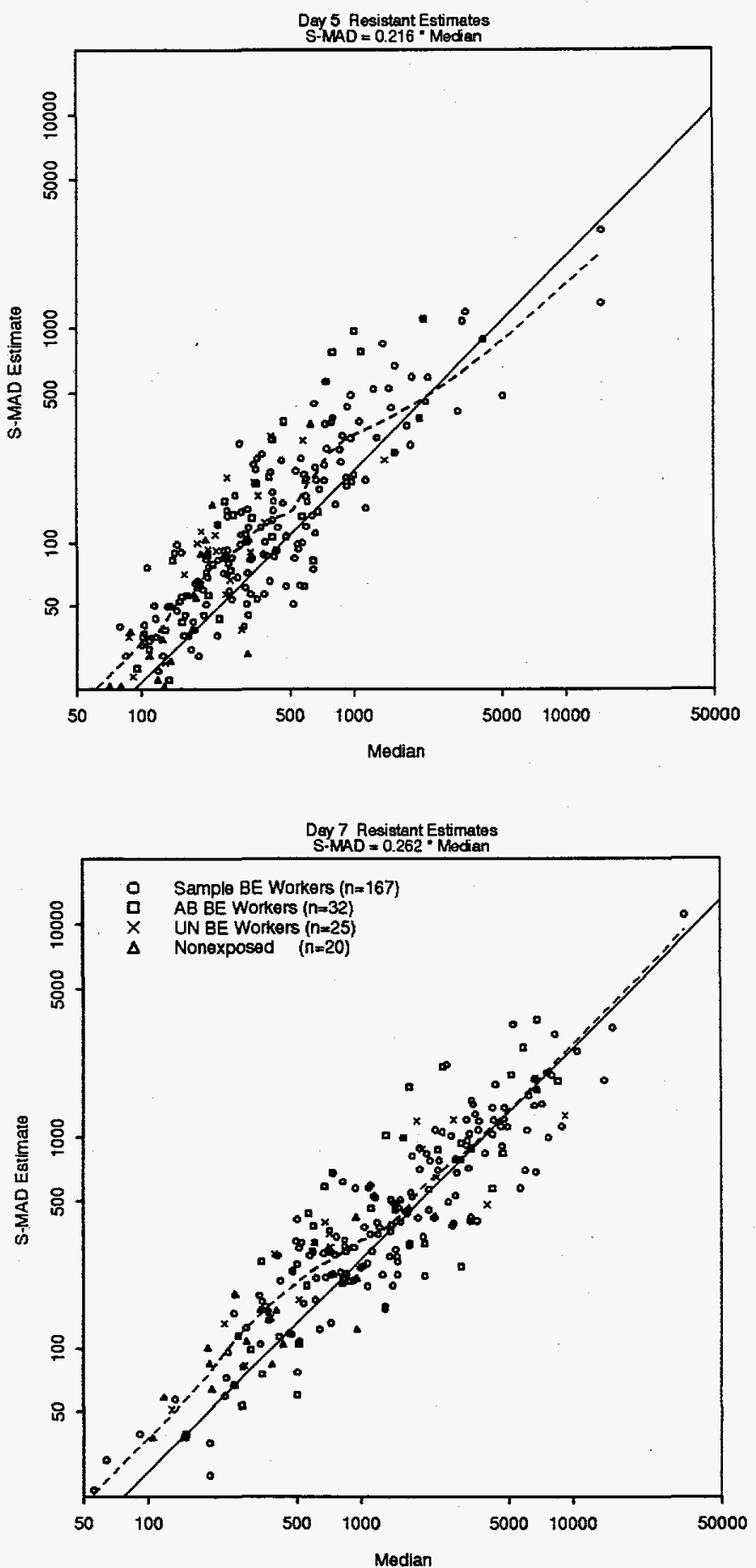

Figure 3: Results for Nonexposed, Beryllium Exposed Workers- Sample, Abnormal, and Unacceptable LPTs. Relationship between the Median, $\tilde{y}$, and the MAD estimate, $\tilde{\sigma}$ of the standard deviation for the control wells on harvest day 5 (top) and harvest day 7 (bottom). The dashed lines are the result of applying scatterplot smoothers to the data. Since results are shown on $\log -\log$ scale the slope of the line is 1. 


\section{Beryllium Exposed Workers Sample (167) and Nonexposed (20) For NJC}

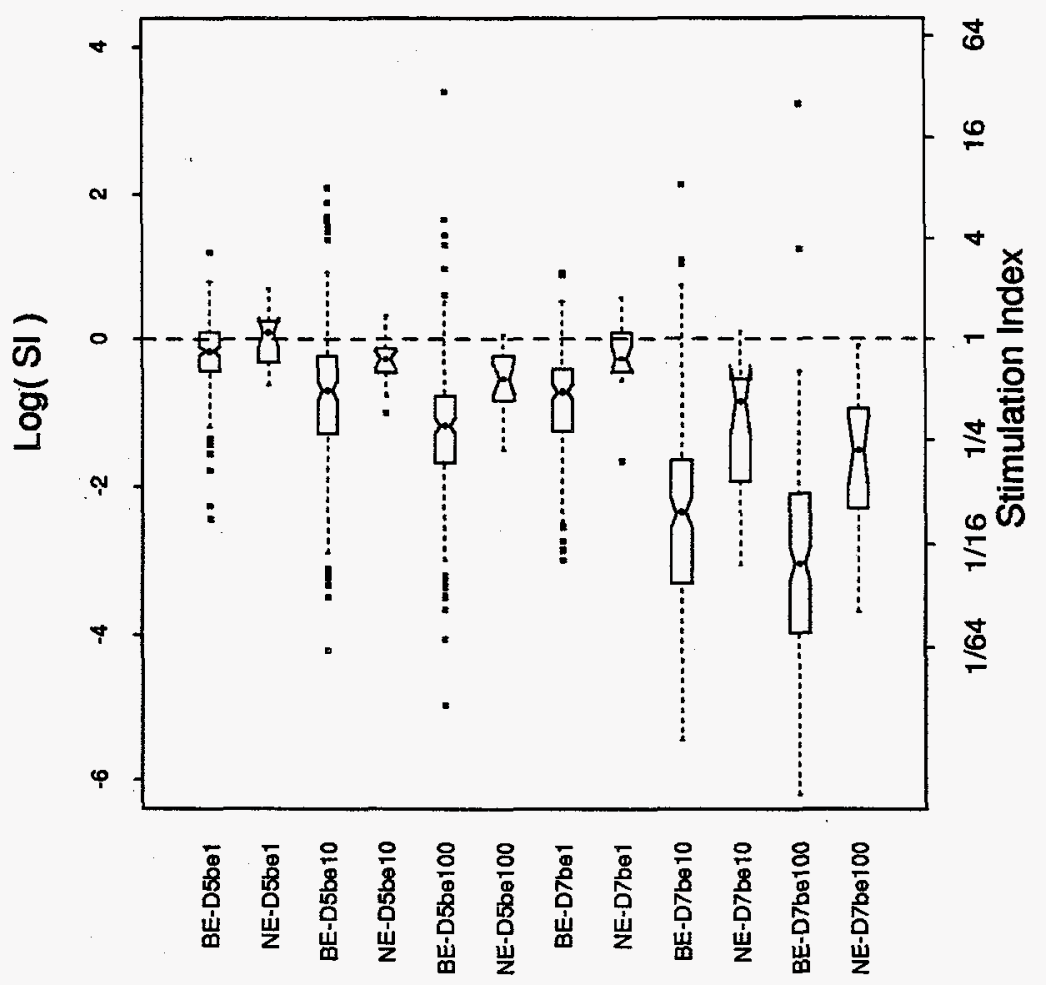

-D5be10 Identifies Sls for Harvest Day 5 and 10 Micro-Mole Be Concentration

Odd Boxes are Beryllium Exposed (BE) Workers Even Boxes are Nonexposed (NE)

Figure 4: Boxplots of SIs for Sample of Beryllium Exposed Workers and Nonexposed Controls. There are Three Beryllium Concentrations on Harvest Days 5 and 7. 
expected if the $\log$ SI values are from a normal distribution with location parameter $M$ (which determines the intercept) and standard deviation $S$ (which determines the slope). Resistant methods were used to estimate the location and scale parameters for the combined data from the $\mathrm{BE}$ and $\mathrm{NE}$ groups. This reflects the assumption that most of beryllium exposed workers do not show an abnormal response, i.e. they look like the nonexposed group. For example, consider the plot for day $5 \mathrm{Be}-10$ in Figure 5 . The $\log$ (SIs) appear to be approximately normal in the center, but there are several values that are larger than expected (these are the points above the line). These "outliers" are SIs that indicate hypersensitivity to beryllium. Compare these results to similar plots for the ORISE data-see [5] Fig. 5.

Normal probability plots for the nonexposed workers alone are shown in Figure 6. Boxplots for each of the data sets considered in this report are shown in Figure 7 . The top panel contains results for day 5 and the bottom panel for day 7 . The NE controls are shown on the left side of each panel. The LAV estimates of the $\log (\mathrm{SI}) \mathrm{s}$ for the 32 Abnormal LPTs are clearly increased and show a different profile than the NEs and BE-sample.

\subsection{Resistant Estimates of the Coefficient of Variation $(\tilde{\phi})$}

Resistant estimates of $\tilde{\phi}$, the coefficient of variation, for the NE LPTs on day 5 and day 7 and for the BE-sample are shown in Figure 8. For example, the boxplot labeled BE5-T is based on a pooled estimates of $\tilde{\phi}$ from the beryllium treated wells on day 5 from the sample of $167 \mathrm{BE}$ workers. The dotted line corresponds to a value of 0.3 for $\phi$. Figure 8 suggests that the internal variability may be slightly greater on day 7 . There is, however, no indication of increased variability in the beryllium stimulated wells.

Log normal probability plots for the $\tilde{\phi}$ values are shown in Figure 9. These plots indicate that $\log (\tilde{\phi})$ is approximately normally distributed with very similar parameters.

Figure 10 shows the distributions of the maximum SIs for the NE, BE (sample), $A B$, and UN data sets. The values for the NE and/or BE-sample are used as the reference group in identification of abnormal LPTs as described in Section 3.1. 
Normal Probability Plots - Log(LAV SIs)-NJC

Day 5 Be-1

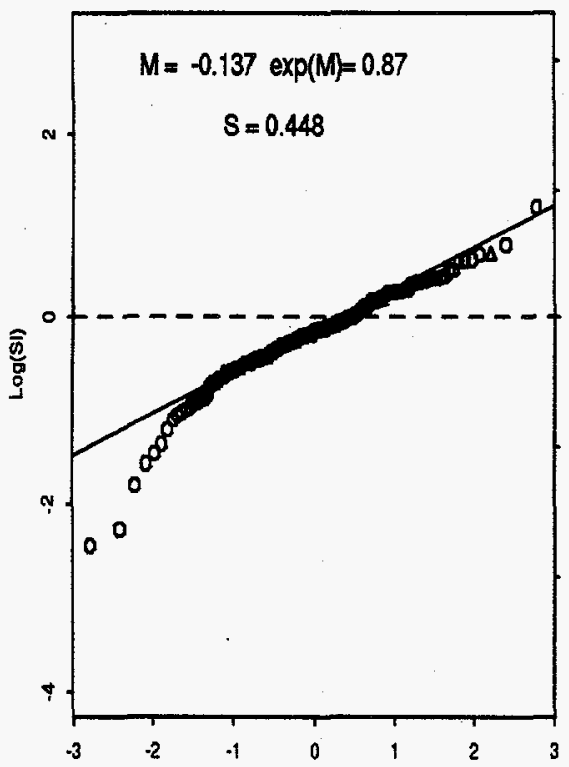

Day 7 Be-1

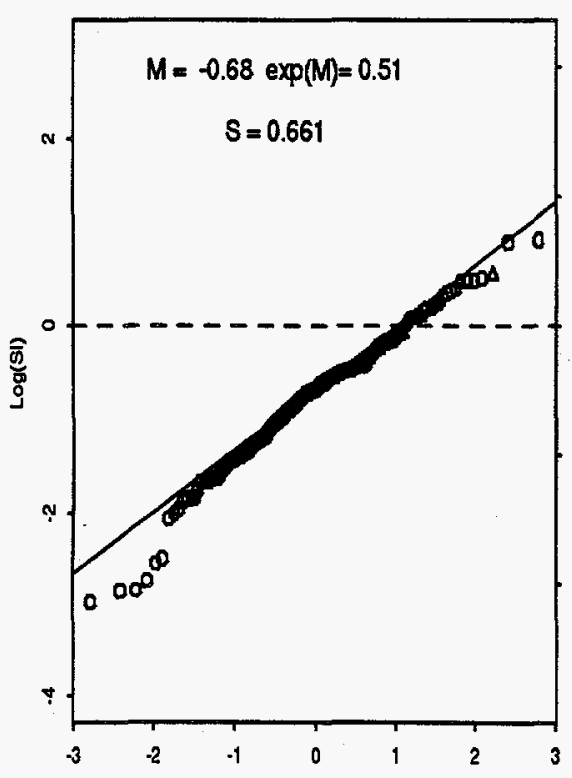

Day 5 Be-10

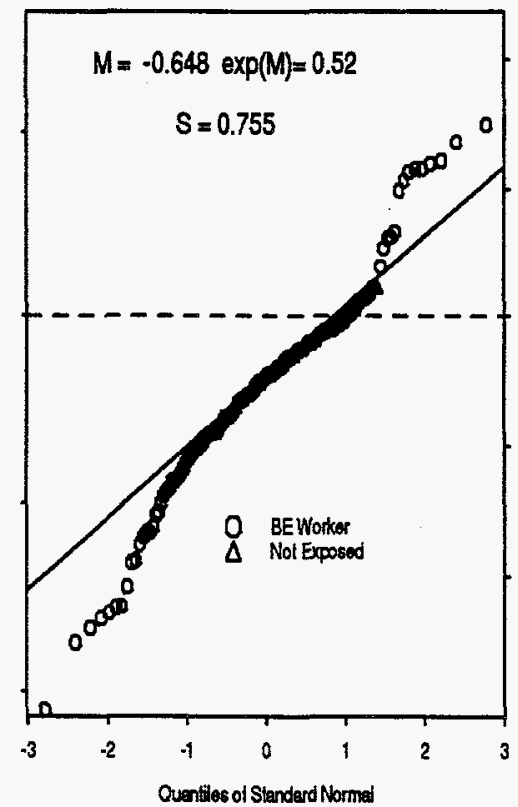

Day 7 Be-10

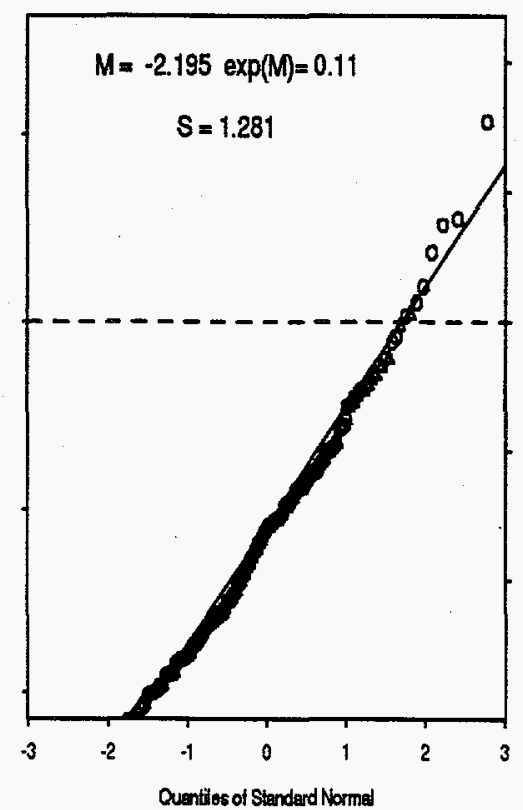

Nota: $M=$ Medien[ $\log (S)] \quad S=S-\operatorname{Med}[\log (S \mid)]$
Day 5 Be-100

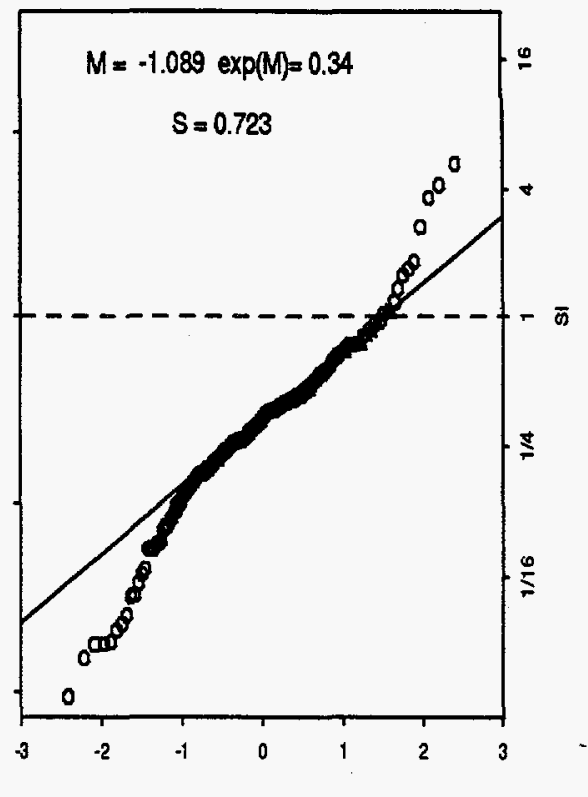

Day 7 Be-100

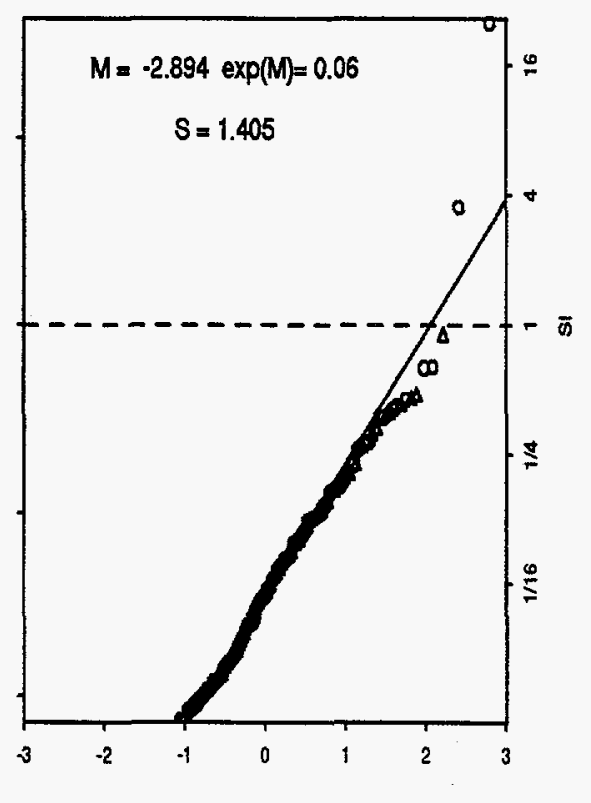

Figure 5: Normal Probability Plots of LAV Estimates of $\log (\mathrm{SI}) \mathrm{s}\left(\tilde{\beta}_{j}\right)$ for Each Beryllium Concentration on Day 5 and Day 7. The Data Values Are Shown on the Vertical Axis. The Median $(\mathrm{M})$ of $\tilde{\beta}_{j}$ and of the SIs $=\exp (\mathrm{M})$ are Listed on Each Plot. 
Normal Probability Plots - Log(LAV SIs)-NJC NONEXPOSED

Day 5 Be-1

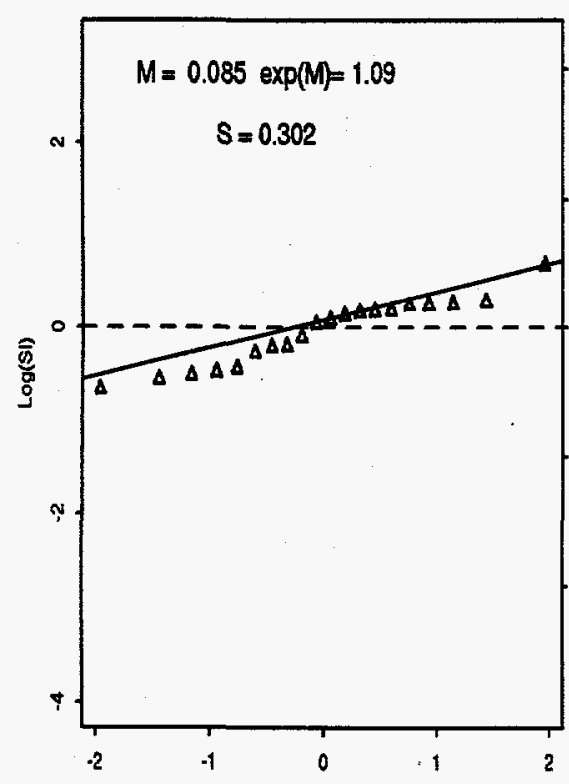

Day 7 Be-1

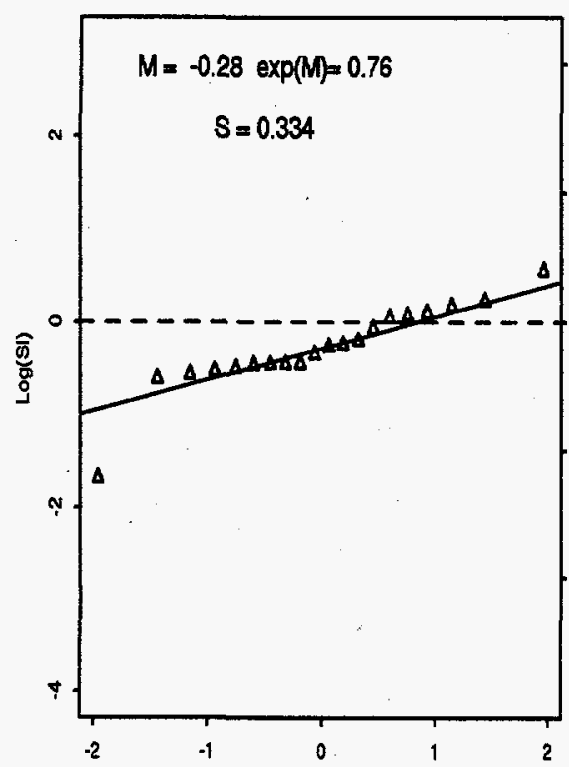

Day 5 Be-10

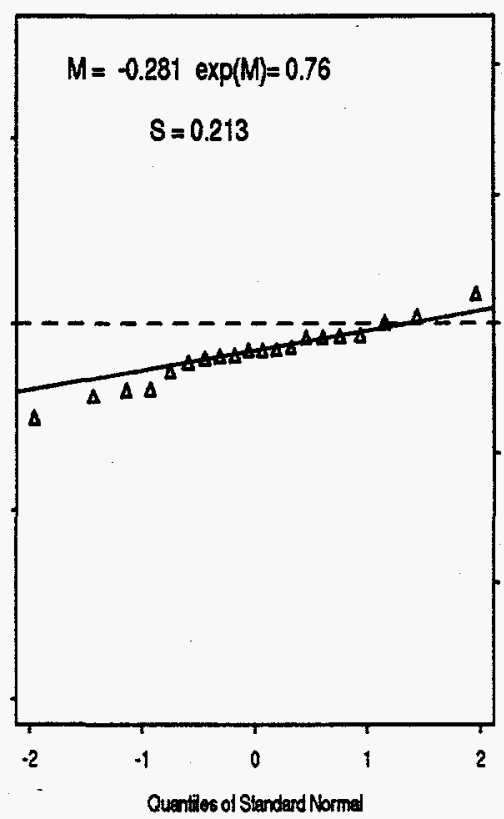

Day 7 Be-10

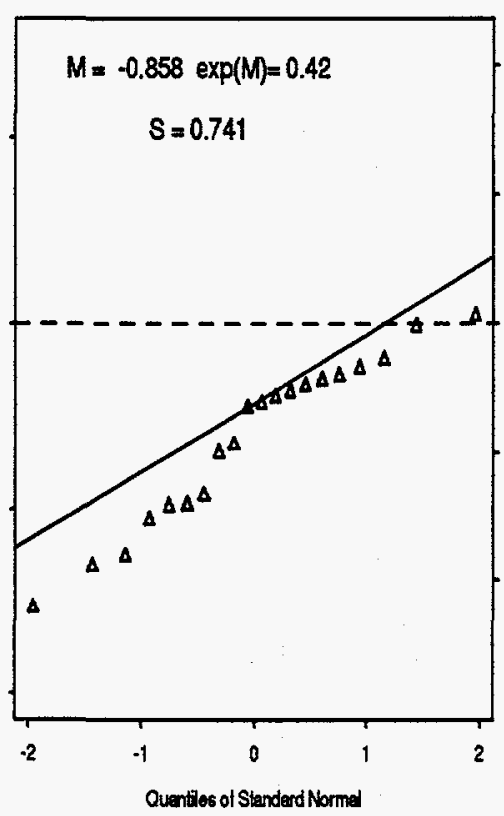

Nolo: $M=\operatorname{Madien}[\log (S)] \quad S=S-\operatorname{Mad}(\log (S))]$
Day $5 \mathrm{Be}-100$

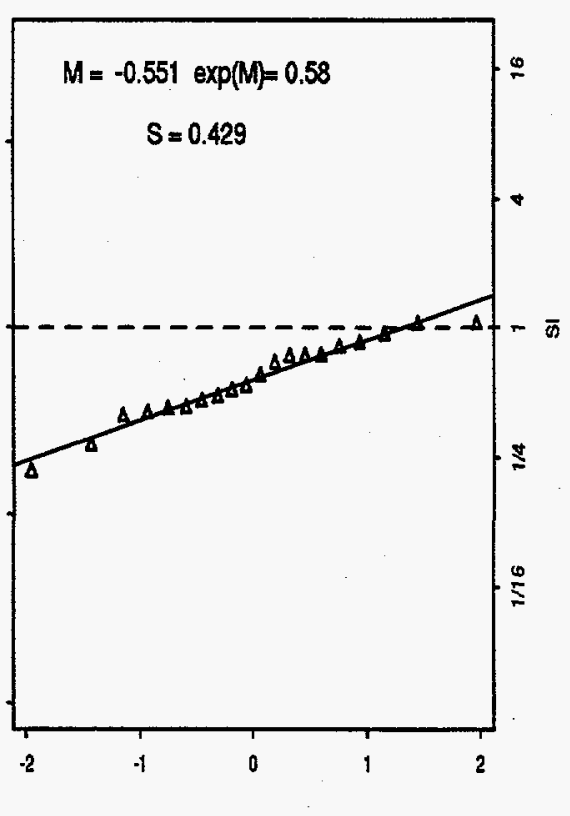

Day 7 Be-100

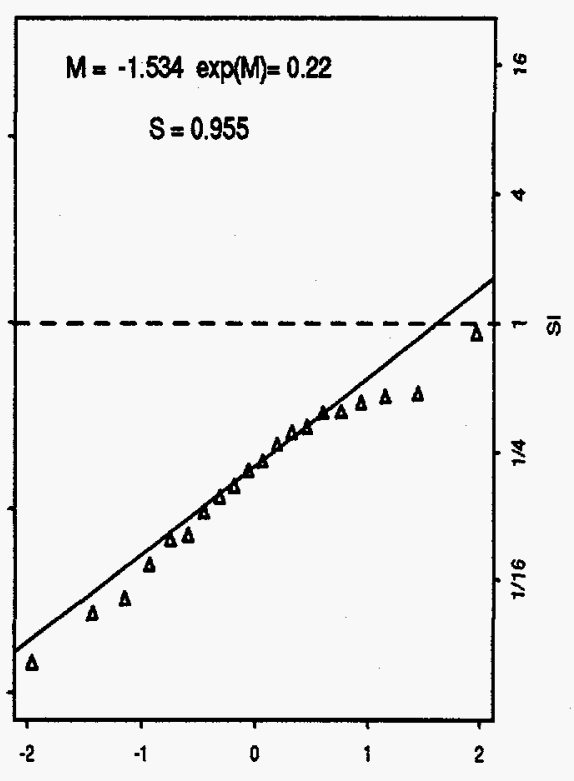

Figure 6: Normal Probability Plots of LAV Estimates of $\log (\mathrm{SI}) \mathrm{s}\left(\tilde{\beta}_{j}\right)$ for Each Beryllium Concentration on Day 5 and Day 7 for nonexposed individuals. The Data Values Are Shown on the Vertical Axis. The Median $(\mathrm{M})$ of $\tilde{\beta}_{j}$ and of the SIs $=\exp (\mathrm{M})$ are Listed on Each Plot. 


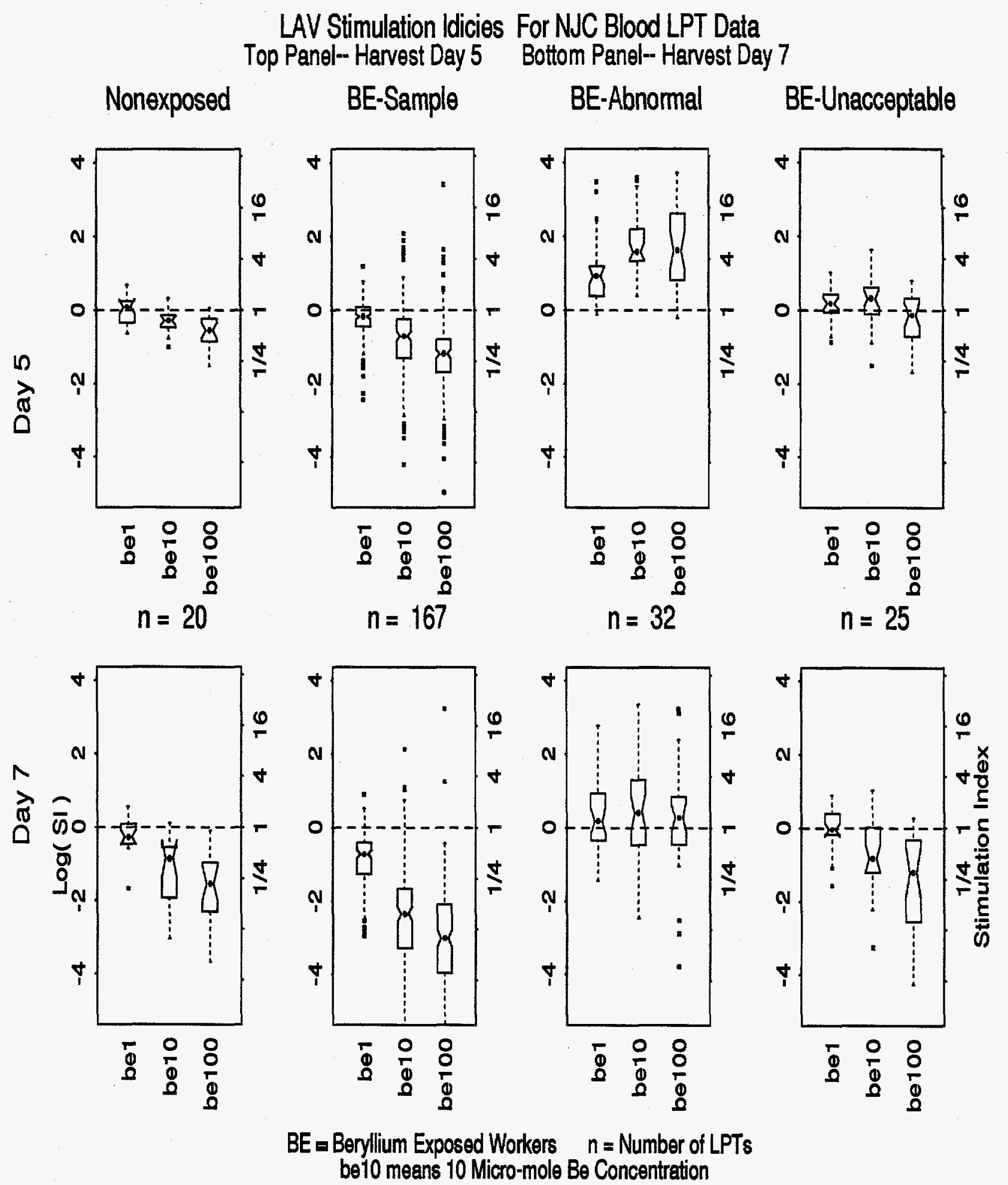

Figure 7: SI Boxplots For NE (Controls) BE-Sample BE-Abnormal and BEUnacceptable Data Sets 


\section{Phitilde (CV) for LAV Method For Log(SI) Beryllium Workers Sample (167) and Nonexposed (20) For NJC}

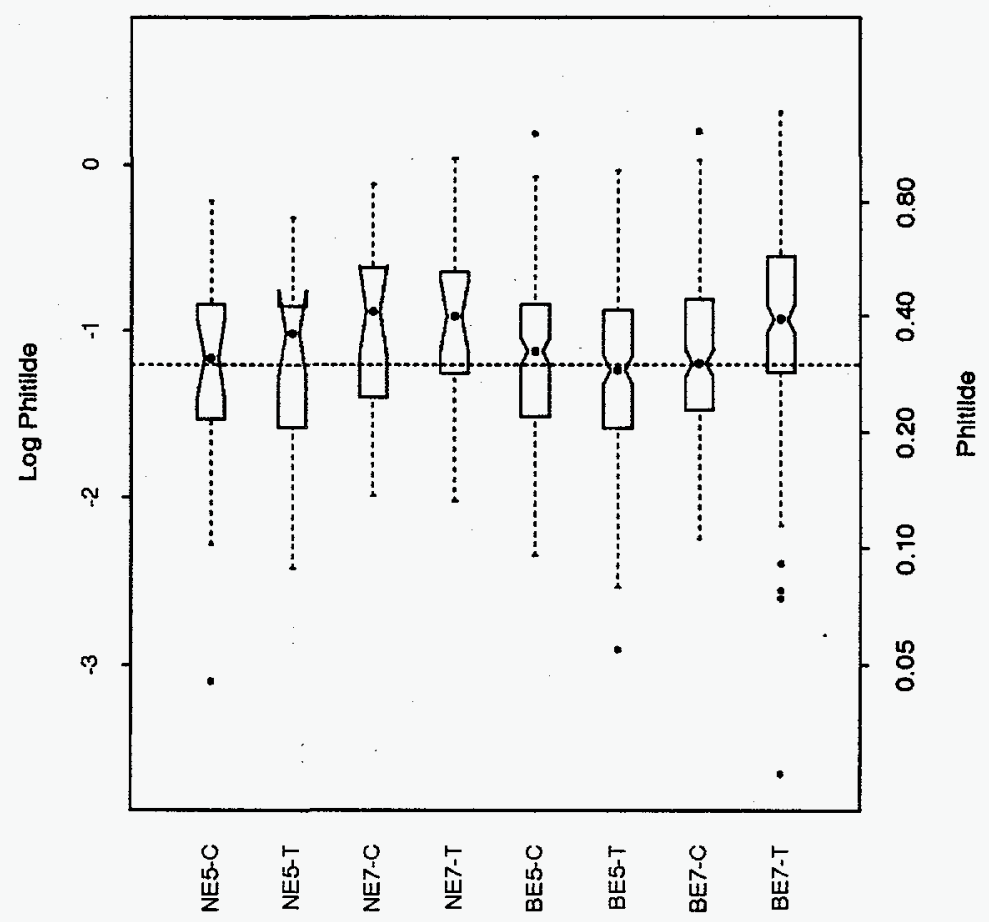

Figure 8: Resistant Estimates of $\tilde{\phi}$ (CV) For Nonexposed and Sample of 167 Beryllium Exposed Workers 


\section{Normal Probability Plots For Log(Phitilde) \\ Beryllium Workers Sample (167) and Nonexposed (20) For NJC}

Day 5 Control Wells

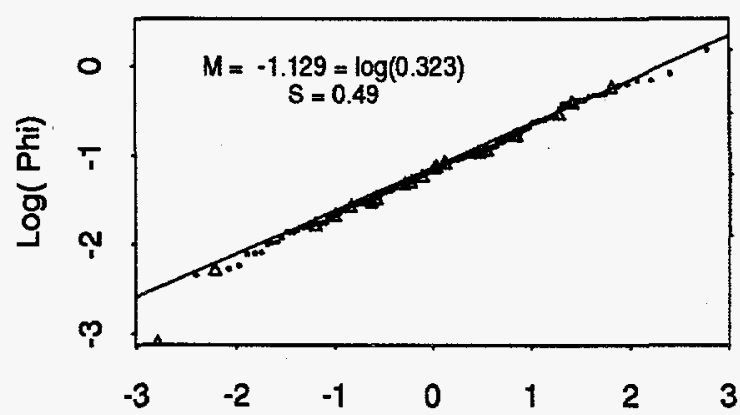

Day 7 Control Wells

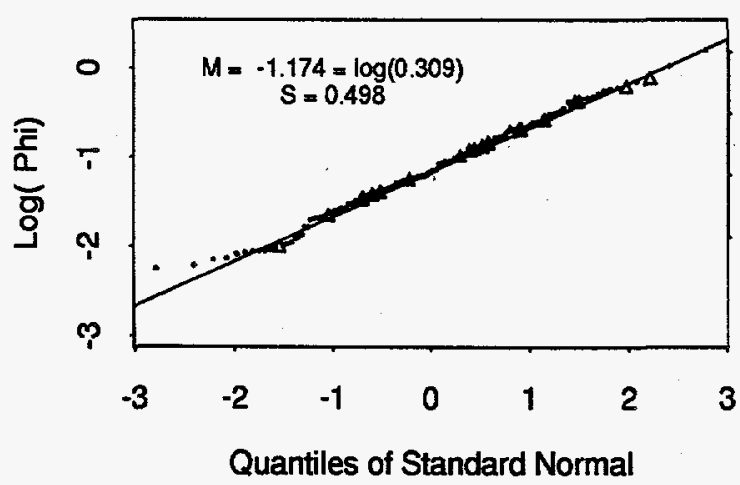

Day 5 Beryllium Wells

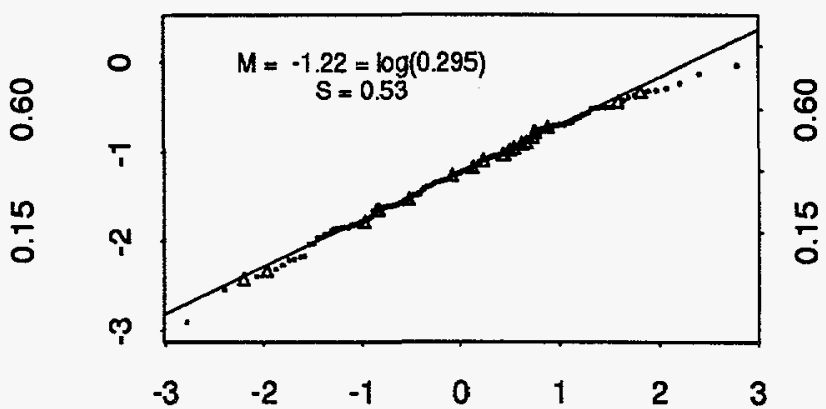

Day 7 Beryllium Wells

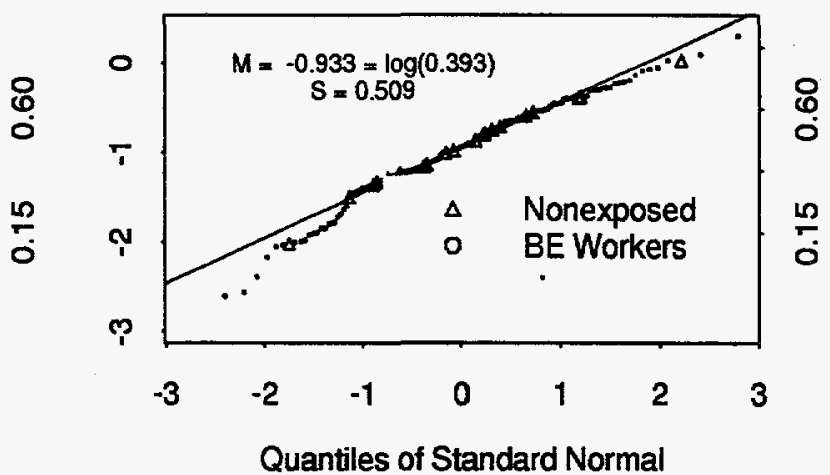

Figure 9: Resistant Estimates of $\tilde{\phi}(\mathrm{CV})$ For 20 Nonexposed and Sample of 167 Beryllium Exposed Workers 


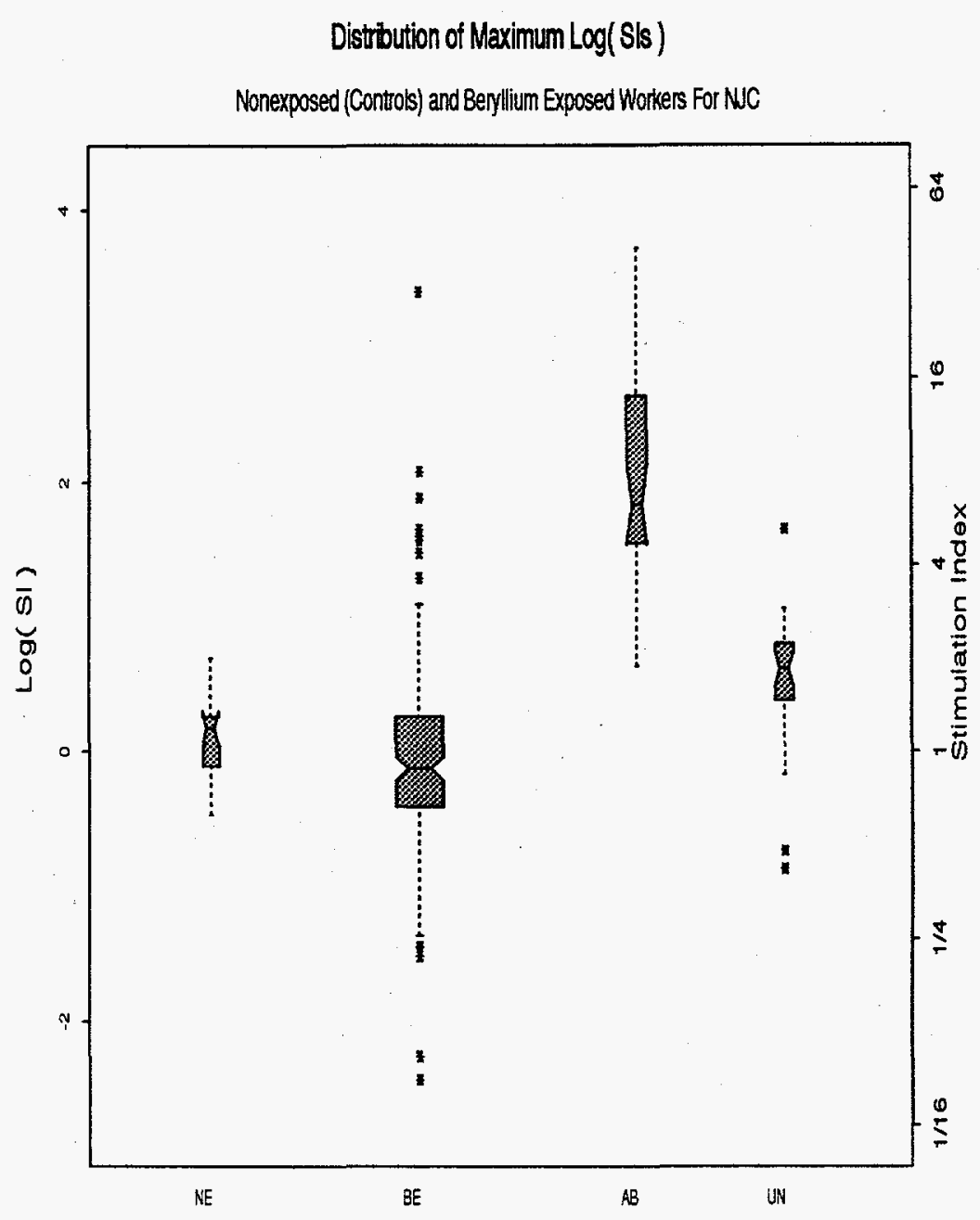

NE-Nonexposed BE-Beyllium Exposed Workers Sample AB-Abnormal UN-Unacceptable

Figure 10: Distributions of $\beta_{i}^{*}$ The Maximum of $\log (\mathrm{SI}) \mathrm{s}$ For NJC Data Sets. There are 32 LPTs in The "Abnormal" Group That Are Confirmed Cases of CBD and 25 LPTs That Were Considered to Be Unacceptable. 


\subsection{Identification Of LPTs With Large SIs}

Table 1 lists the LPTs with large SIs based on Method 1 (Section 3.1). The reference data base used was the nonexposed controls. There were 11 LPTs in the BE-sample and 4 LPTs in the unacceptables that were identified as having at least two large SIs. All 32 of the abnormal LPTs were identified as having at least two large SIs so they were not included in Table 1.

Table 2 lists the SIs for LPTs with large SIs based on Method 1A (Section 3.2). The reference data base used was the nonexposed controls. There were 19 LPTs in the BE-sample and 14 LPTs in the unacceptables that were identified as having at least two large SIs. All 32 of the abnormal LPTs were identified as having at least two large SIs so they were not included in Table 2.

Table 3 gives the standardized deviates defined in Section 3.3 for LPTs with large SIs based on Method 2. The reference data base used was the nonexposed controls combined with the BE-sample, and $z_{p}$ was $z .9568=1.715$. The values of $\tilde{\mu}_{j}$ and $\tilde{s}_{j}$ are given at the bottom of Table 3 . The SI value that had to be exceeded for each $\mathrm{Be}$ concentration is in the last row of Table 3. An LPT is abnormal if at least two of the standardized deviates exceed 1.715. There were $13 \mathrm{LPTs}$ in the BE-sample and $9 \mathrm{LPTs}$ in the unacceptables that were identified as having at least two large SIs. All 32 of the abnormal LPTs were identified as having at least two large SIs so they were not included in Table 3. An approximate lower bound (see Section 3.3) on the probability of a false positive is $1-\left[p^{6}+6(1-p) p^{5}\right]=.025$. 
Table 1: Method 1 Results: Log(SI)s (top panel) and SIs ( bottom panel ) for Individuals from the BE Sample (167) and Unacceptables (25) with "abnormal" LPTs. The values for $M$ and $S$ (Section 3.1 ) are 0.170 and 0.179 , respectively, cut $=0.521$ is the cut point for a large $\log (\mathrm{SI})-\exp (.521)=1.68$. The reference data base used was the 20 LPTs for Nonexposed individuals. ALL abnormal LPTs had at least two large SIs and are not listed.

\begin{tabular}{|c||r|r|r||r|r|r|}
\hline \multicolumn{1}{|c||}{ ID } & \multicolumn{3}{|c||}{ Day 5 } & \multicolumn{3}{c|}{ Day 7 } \\
\cline { 2 - 7 } Log(SI)s & be 1 & be 10 & be 100 & be 1 & be 10 & be 100 \\
BS1033 & 0.19 & 1.65 & 0.15 & -0.07 & 1.03 & -1.35 \\
BS1034 & 0.31 & 0.92 & 0.60 & -0.50 & -1.29 & -1.68 \\
BS1035 & 0.63 & 1.57 & 0.97 & -1.43 & -2.47 & -3.78 \\
BS1091 & -0.10 & 1.37 & 1.65 & -0.42 & 0.20 & 1.25 \\
BS1259 & 0.62 & -0.71 & -1.42 & 0.90 & -2.09 & -4.08 \\
BS1269 & 1.20 & 1.60 & 1.43 & -0.55 & -0.72 & -0.44 \\
BS1271 & 0.68 & 0.86 & 0.03 & 0.20 & 1.09 & -2.30 \\
BS1315 & 0.00 & 0.74 & 1.29 & -0.76 & -0.80 & -1.32 \\
BS1316 & -0.12 & 1.70 & 3.40 & 0.49 & 2.13 & 3.24 \\
BS1321 & 0.80 & 1.47 & -0.20 & -0.72 & -2.30 & -2.89 \\
BS472 & 0.38 & 1.89 & 0.45 & 0.26 & 0.74 & -0.99 \\
BU1033 & 0.19 & 1.65 & 0.15 & -0.07 & 1.03 & -1.35 \\
BU2685 & 1.05 & 1.06 & 0.02 & 0.57 & -0.42 & -1.20 \\
BU3064 & 0.36 & 0.77 & 0.59 & 0.29 & -0.15 & 0.03 \\
BU3287 & 0.96 & 0.07 & 0.61 & 0.47 & -0.32 & 0.25 \\
\hline SIs & & & & & & \\
BS1033 & 1.20 & 5.22 & 1.16 & 0.93 & 2.80 & 0.26 \\
BS1034 & 1.36 & 2.50 & 1.82 & 0.61 & 0.28 & 0.19 \\
BS1035 & 1.88 & 4.80 & 2.63 & 0.24 & 0.08 & 0.02 \\
BS1091 & 0.90 & 3.95 & 5.22 & 0.66 & 1.22 & 3.47 \\
BS1259 & 1.87 & 0.49 & 0.24 & 2.47 & 0.12 & 0.02 \\
BS1269 & 3.31 & 4.94 & 4.19 & 0.58 & 0.49 & 0.64 \\
BS1271 & 1.98 & 2.37 & 1.03 & 1.22 & 2.98 & 0.10 \\
BS1315 & 1.00 & 2.10 & 3.64 & 0.47 & 0.45 & 0.27 \\
BS1316 & 0.89 & 5.45 & 29.85 & 1.63 & 8.45 & 25.41 \\
BS1321 & 2.21 & 4.37 & 0.82 & 0.49 & 0.10 & 0.06 \\
BS472 & 1.46 & 6.62 & 1.56 & 1.30 & 2.10 & 0.37 \\
BU1033 & 1.20 & 5.22 & 1.16 & 0.93 & 2.80 & 0.26 \\
BU2685 & 2.85 & 2.88 & 1.02 & 1.77 & 0.66 & 0.30 \\
BU3064 & 1.43 & 2.16 & 1.80 & 1.34 & 0.86 & 1.03 \\
BU3287 & 2.61 & 1.07 & 1.84 & 1.61 & 0.73 & 1.28 \\
\hline
\end{tabular}


Table 2: Method 1A Results: SIs for Beryllium Workers Sample (167), Unacceptables(25) LPTs For NJC Data. The values for M and S (Section 3.2) are -0.197 and 0.240 , respectively, and $c u t=0.274$ is the cut point for a large $\log (\mathrm{SI})$ and $\exp (0.274)=$ 1.32. The Reference Data Base used was made up of the 20 LPTs for Nonexposed and $p=0.975$, with a false positive rate of about 2.5 percent. ALL abnormal LPTs had at least two large SIs and are not listed.

\begin{tabular}{|c||c|c|c||c|c|c|}
\hline \multicolumn{1}{|c||}{ ID } & \multicolumn{3}{|c|}{ Day 5 } & \multicolumn{3}{c|}{ Day 7} \\
\cline { 2 - 7 } & be 1 & be 10 & be 100 & be 1 & be 10 & be 100 \\
\hline BS1027 & 0.57 & 8.02 & 0.56 & 0.62 & 1.45 & 0.10 \\
BS1033 & 1.20 & 5.22 & 1.16 & 0.93 & 2.80 & 0.26 \\
BS1034 & 1.36 & 2.50 & 1.82 & 0.61 & 0.28 & 0.19 \\
BS1035 & 1.88 & 4.80 & 2.63 & 0.24 & 0.08 & 0.02 \\
BS1087 & 1.48 & 1.27 & 1.67 & 0.20 & 0.14 & 0.20 \\
BS1091 & 0.90 & 3.95 & 5.22 & 0.66 & 1.22 & 3.47 \\
BS1259 & 1.87 & 0.49 & 0.24 & 2.47 & 0.12 & 0.02 \\
BS1269 & 3.31 & 4.94 & 4.19 & 0.58 & 0.49 & 0.64 \\
BS1271 & 1.98 & 2.37 & 1.03 & 1.22 & 2.98 & 0.10 \\
BS1315 & 1.00 & 2.10 & 3.64 & 0.47 & 0.45 & 0.27 \\
BS1316 & 0.89 & 5.45 & 29.85 & 1.63 & 8.45 & 25.41 \\
BS1321 & 2.21 & 4.37 & 0.82 & 0.49 & 0.10 & 0.06 \\
BS425 & 1.44 & 0.90 & 0.54 & 1.62 & 0.86 & 0.28 \\
BS472 & 1.46 & 6.62 & 1.56 & 1.30 & 2.10 & 0.37 \\
BS731 & 1.32 & 0.78 & 0.31 & 1.46 & 0.14 & 0.07 \\
BS818 & 1.54 & 1.03 & 0.96 & 1.49 & 0.14 & 0.11 \\
BS819 & 1.65 & 1.20 & 0.65 & 2.42 & 0.51 & 0.42 \\
BS824 & 1.53 & 0.29 & 0.32 & 1.38 & 0.06 & 0.05 \\
BS826 & 1.48 & 1.73 & 1.35 & 0.66 & 0.68 & 0.63 \\
BU1033 & 1.20 & 5.22 & 1.16 & 0.93 & 2.80 & 0.26 \\
BU1960 & 1.34 & 2.24 & 0.50 & 0.97 & 0.42 & 0.06 \\
BU2167 & 1.54 & 1.84 & 1.01 & 1.35 & 1.43 & 0.59 \\
BU2172 & 0.63 & 1.37 & 0.89 & 1.50 & 1.71 & 0.72 \\
BU2282 & 1.03 & 1.46 & 1.38 & 1.88 & 1.00 & 1.30 \\
BU2685 & 2.85 & 2.88 & 1.02 & 1.77 & 0.66 & 0.30 \\
BU2947 & 1.45 & 1.65 & 1.45 & 0.89 & 1.15 & 0.80 \\
BU3064 & 1.43 & 2.16 & 1.80 & 1.34 & 0.86 & 1.03 \\
BU3068 & 2.59 & 1.46 & 0.93 & 0.92 & 0.35 & 0.18 \\
BU3175 & 1.15 & 2.06 & 1.50 & 1.47 & 1.35 & 0.96 \\
BU3251 & 1.37 & 1.09 & 1.82 & 0.51 & 0.11 & 0.11 \\
BU3287 & 2.61 & 1.07 & 1.84 & 1.61 & 0.73 & 1.28 \\
BU3470 & 0.61 & 2.02 & 0.71 & 1.60 & 0.44 & 0.81 \\
BU819 & 1.65 & 1.20 & 0.65 & 2.42 & 0.51 & 0.42 \\
\hline
\end{tabular}


Table 3: Method 2 Results: Standardized Deviates (see Section 3.3 ) For Beryllium Exposed Workers and Unacceptable LPTs. The value of $p=0.9568$ so the false positive rate is about 2.5 percent. ALL abnormal LPTs had at least two large SIs and are not listed.

\begin{tabular}{|c||r|r|r||r|r|r|}
\hline \multicolumn{1}{|c||}{ ID } & \multicolumn{3}{c||}{ Day 5 } & \multicolumn{3}{c|}{ Day 7 } \\
\cline { 2 - 7 } & be 1 & be 10 & be 100 & be 1 & be 10 & be 100 \\
\hline BS1027 & -0.94 & 3.62 & 0.70 & 0.31 & 2.00 & 0.41 \\
BS1033 & 0.72 & 3.05 & 1.71 & 0.92 & 2.52 & 1.10 \\
BS1034 & 0.99 & 2.07 & 2.33 & 0.28 & 0.71 & 0.86 \\
BS1035 & 1.72 & 2.94 & 2.85 & -1.14 & -0.22 & -0.63 \\
BS1091 & 0.08 & 2.68 & 3.79 & 0.39 & 1.87 & 2.95 \\
BS1261 & -0.20 & 2.97 & 0.75 & 0.21 & 1.75 & 0.57 \\
BS1269 & 2.98 & 2.97 & 3.49 & 0.20 & 1.15 & 1.74 \\
BS1271 & 1.83 & 2.00 & 1.54 & 1.33 & 2.57 & 0.42 \\
BS1315 & 0.31 & 1.84 & 3.29 & -0.13 & 1.09 & 1.12 \\
BS1316 & 0.04 & 3.10 & 6.20 & 1.77 & 3.38 & 4.36 \\
BS1321 & 2.08 & 2.81 & 1.22 & -0.06 & -0.08 & 0.00 \\
BS472 & 1.15 & 3.36 & 2.12 & 1.43 & 2.29 & 1.35 \\
BS826 & 1.18 & 1.58 & 1.92 & 0.40 & 1.41 & 1.73 \\
BU1033 & 0.72 & 3.05 & 1.71 & 0.92 & 2.52 & 1.10 \\
BU2172 & -0.72 & 1.27 & 1.34 & 1.64 & 2.13 & 1.83 \\
BU2282 & 0.36 & 1.36 & 1.95 & 1.98 & 1.72 & 2.25 \\
BU2685 & 2.64 & 2.26 & 1.53 & 1.89 & 1.39 & 1.21 \\
BU2947 & 1.14 & 1.52 & 2.02 & 0.85 & 1.82 & 1.90 \\
BU3064 & 1.10 & 1.88 & 2.31 & 1.47 & 1.60 & 2.08 \\
BU3175 & 0.61 & 1.82 & 2.07 & 1.61 & 1.95 & 2.03 \\
BU3287 & 2.45 & 0.95 & 2.35 & 1.75 & 1.47 & 2.24 \\
BU3470 & -0.79 & 1.79 & 1.03 & 1.74 & 1.07 & 1.91 \\
Med & -0.14 & -0.65 & -1.09 & -0.68 & -2.19 & -2.89 \\
Smad & 0.45 & 0.75 & 0.72 & 0.66 & 1.28 & 1.41 \\
Cut SI & 1.88 & 1.91 & 1.16 & 1.57 & 1.00 & 0.62 \\
\hline
\end{tabular}


Table 4: Beryllium Exposed Workers Classified as Abnormal by at Least One Method ${ }^{a}$

\begin{tabular}{ccccll}
\multicolumn{4}{c}{ Method } & \multicolumn{2}{c}{ NJC } \\
ID & 1 & 1A & $\mathbf{2}$ & Result & Retest $^{b}$ \\
\hline BS 425 & N & A & N & N & \\
BS 731 & N & A & N & N & \\
BS 818 & N & A & N & N & \\
BS 819 & N & A & N & U & N \\
BS 824 & N & A & N & N & \\
BS 826 & N & A & N & N & \\
BS1027 & N & A & A & B & B A (BE Sensitized) \\
BS1033 & A & A & A & U & N A U (Equivocal) \\
BS1034 & A & A & A & B & B N \\
BS1087 & N & A & N & B & B U N \\
BS1259 & A & A & N & N & \\
BS1261 & N & N & A & B & Unknown \\
BS1271 & A & A & A & U & N \\
\hline
\end{tabular}

\footnotetext{
${ }^{a}$ Seven additional workers that are known $\mathrm{CBD}$ cases in the $\mathrm{BE}$ sample were called abnormal by all three methods and are not listed.

${ }^{b}$ NJC retest results: A-abornmal, B-borderline, N-normal, Uunacceptable.
}

\section{Comparison of The Three Methods}

All three methods (1 1A and 2) for identifying abnormal LPTs, based on the LAV method for estimating the SIs, correctly identified the 32 known CBD cases as abnormal.

All three methods (see Tables 1-3) also correctly identified the seven BE workers with CBD. They are BS1035, BS1091, BS1269, BS1315, BS1316, BS1321, BS472. Method 1 (see Table 1) called an additional 4 BE workers abnormal. Method 2 (see Table 3) called an additional 6 BE workers abnormal. Method 1A (see Table 2) called an additional $12 \mathrm{BE}$ workers abnormal, some of whom were included in Table 1 and Table 3. Thirteen beryllium exposed workers were called abnormal by at least one of the three methods-see Table 4 for a summary of their results. 


\subsection{Classification of Unacceptable LPTs}

Table 5: Summary For NJC Unacceptable LPTs

A-abnormal U-unacceptable B-borderline N-normal

\begin{tabular}{lccccll} 
ID & CV & Meth-1 & Meth-1A & Meth-2 & RETEST & RESULTS \\
\hline BU0819 & 0.86 & $\mathrm{n}$ & $\mathrm{A}$ & $\mathrm{n}$ & $\mathrm{N}$ & \\
BU0606 & 0.34 & $\mathrm{n}$ & $\mathrm{n}$ & $\mathrm{n}$ & $\mathrm{N}$ & \\
BU3470 & 0.69 & $\mathrm{n}$ & $\mathrm{A}$ & $\mathrm{A}$ & $\mathrm{N}$ & \\
BU3454 & 0.45 & $\mathrm{n}$ & $\mathrm{n}$ & $\mathrm{n}$ & $\mathrm{N}$ & \\
BU3287 & 0.47 & $\mathrm{~A}$ & $\mathrm{~A}$ & $\mathrm{~A}$ & $\mathrm{~A}$ & Be Sen \\
BU3251 & 0.35 & $\mathrm{n}$ & $\mathrm{A}$ & $\mathrm{n}$ & $\mathrm{N}$ & \\
BU3175 & 0.46 & $\mathrm{n}$ & $\mathrm{A}$ & $\mathrm{A}$ & $\mathrm{A} \mathrm{B} \mathrm{B}$ & Equivocal \\
BU3163 & 0.70 & $\mathrm{n}$ & $\mathrm{n}$ & $\mathrm{n}$ & $4 \mathrm{Us}$ & CBD see BU1960 \\
BU3068 & 0.47 & $\mathrm{n}$ & $\mathrm{A}$ & $\mathrm{n}$ & $\mathrm{N}$ & \\
BU3064 & 0.61 & $\mathrm{~A}$ & $\mathrm{~A}$ & $\mathrm{~A}$ & $\mathrm{~N} ?$ & CBD \\
BU3056 & 0.56 & $\mathrm{n}$ & $\mathrm{n}$ & $\mathrm{n}$ & $\mathrm{N}$ & \\
BU2947 & 0.58 & $\mathrm{n}$ & $\mathrm{A}$ & $\mathrm{A}$ & $\mathrm{A} \mathrm{B}$ & Equivocal \\
BU2685 & 0.53 & $\mathrm{~A}$ & $\mathrm{~A}$ & $\mathrm{~A}$ & $\mathrm{~A}$ & Be Sen \\
BU2680 & 0.51 & $\mathrm{n}$ & $\mathrm{n}$ & $\mathrm{n}$ & $\mathrm{A} \mathrm{A}$ & Not Evaluated \\
BU2282 & 0.81 & $\mathrm{n}$ & $\mathrm{A}$ & $\mathrm{A}$ & $\mathrm{A} \mathrm{B}$ & Equivocal \\
BU2172 & 0.44 & $\mathrm{n}$ & $\mathrm{A}$ & $\mathrm{A}$ & $\mathrm{A} \mathrm{B} \mathrm{B}$ & CBD \\
BU2167 & 0.47 & $\mathrm{n}$ & $\mathrm{A}$ & $\mathrm{n}$ & $\mathrm{N} \mathrm{B}$ & \\
BU1960 & 0.68 & $\mathrm{n}$ & $\mathrm{A}$ & $\mathrm{n}$ & $4 \mathrm{U}$ & CBD see BU3163 \\
BU1805 & 0.91 & $\mathrm{n}$ & $\mathrm{n}$ & $\mathrm{n}$ & $\mathrm{N} \mathrm{U}$ & \\
BU1033 & 0.58 & $\mathrm{~A}$ & $\mathrm{~A}$ & $\mathrm{~A}$ & N A U & Equivocal \\
\hline \hline
\end{tabular}

${ }^{a} \mathrm{BU} 3163$ and BU1960 are for the same person.

${ }^{b}$ BU3064 repeat was $\mathrm{N}$, but this person was abnormal $(\mathrm{x} 2)$ at the other laboratory involved in this study.

${ }^{c}$ BU2680 re-tested abnormal. This person's LPT had very high phitilde values: day 5 controls $=0.565$ day 7 control $=0.569$, and would clearly be a candidate for the designation unacceptable due to too much variability (if I had one).

Table 5 summarizes the results for each of the unacceptable LPTs that were due to "high variability". Five of the original LPTs are not shown because they were not called unacceptable because of high variability. BU877, BU537, and BU475 were unacceptable due to high control counts; BU3532 had very low counts; and BU2629 was not unacceptable by any criteria. The results in Table 5 are of interest since each of the workers with unacceptable LPTs had at least one additional LPT at NJC and 
the retest results are given in Table 5. Two of these (BU3163 and BU1960) are for the same person, a confirmed CBD case. Both of the $\tilde{\phi}$ values are very high $(0.70$ and 0.68$)$ and BU1960 was called abnormal by Method 1A.

One LPT that was called abnormal (BU3064) using LAV SIs by all three methods was normal on retest by NJC, but was called abnormal twice at a second lab. BU2680 was called normal using LAV estimates by all three methods, and was called abnormal in two retests at NJC. The CBD status of this patient has not been evaluated.

\subsubsection{Method 1 Results Based On Maximum SI}

Table 6 summarizes the results of the retest LPTs that were done for each of the original unacceptable LPTs using Method 1. For example, row two indicates that 3 of the Method 1 abnormal LPTs were abnormal on retest, and row five shows that 5 of the normal LPTs were abnormal. This suggests that Method 1 may be missing some of the beryllium sensitized individuals.

\subsubsection{Method 1A Results Based On Second Largest SI}

Table 7 summarizes the results of the retest LPTs that were done for each of the original unacceptable LPTs using Method 1A. Row two indicates that seven of the Method 1A abnormal LPTs were abnormal on retest, and only one of the normal LPTs was abnormal on retest (see row 5). The first row of Table 7 shows that seven of the abnormals were normal on retest (based on NJC method), suggesting that this method may have more false positive results.

\subsubsection{Method 2 Results Based On Each Day/Concentration}

Table 8 summarizes the results of the retest LPTs that were done for each of the original unacceptable LPTs using Method 2. Seven of the eight abnormals were called abnormal on retest, and only three of the abnormals were called normal.

Note that some NJC Unacceptables had more than one RETEST ( see Table 5), and all of the retest results were used to obtain Tables 6-8. 
Table 6: RETEST Results For Method 1 Based on Maximum SI Distribution (See Section 3.1 And Column 3 of Table 5)

\begin{tabular}{ccc}
\hline LPT Evaluated & NJC Repeat & Number \\
\hline A & N & 2 \\
A & A & 3 \\
A & U & 1 \\
& & \\
N & N & 9 \\
N & A & 5 \\
N & U & 3 \\
\hline
\end{tabular}

Table 7: RETEST Results For Method 1A Based on Second Largest SI Distribution (See Section 3.2 And Column 4 of Table 5)

\begin{tabular}{ccc}
\hline LPT Evaluated & NJC Repeat & Number \\
\hline A & N & 7 \\
A & A & 7 \\
A & U & 2 \\
& & \\
N & N & 4 \\
N & A & 1 \\
N & U & 1 \\
\hline
\end{tabular}

Table 8: RETEST Results For Method 2(see Section 3.3 And Column 5 of Table 5)

\begin{tabular}{ccc}
\hline LPT Evaluated & NJC Repeat & Number \\
\hline A & N & 3 \\
A & A & 7 \\
A & U & 1 \\
& & \\
N & N & 8 \\
N & A & 1 \\
N & U & 3 \\
\hline
\end{tabular}




\section{Criteria For Unacceptable LPTs}

One feature of the LAV approach is that it is not necessary to declare LPTs as unacceptable because of "high variability" in the well counts based on the CV. There are however situations that may result in an unacceptable LPT. Data may be considered unacceptable if any of the following situations occur:

1. Control well counts are too low or too high relative to plate background due to laboratory error. Sources of technical error might include mistakes in pipetting, such as failures to add appropriate numbers of cells to individual wells, lack of addition or double addition of tritiated thymidine to specific wells, or improper washing of filters resulting in residual counts of unincorporated thymidine, or smearing of radiolabel across the filter paper.

2. Positive control SIs for ConA or PHA SIs are low (indicating low cell viability).

3. The internal variability for a quadruplicate of Be stimulated cells is "too high" for at least two Be concentrations, provided this is due to at least two counts that are "two low", i.e. close to background for the plate indicating laboratory error-See Section 6.1.

4. The internal variability for the control wells is too high on day 5 or day 7 . An approximate critical value for $\tilde{\phi}_{L}$ can be obtained using an empirical or theoretical approach-see Section 6.1.

5. At least four SIs are "too low" indicating cell killing. An SI is too low if it is significantly below the null value of one (zero on the $\log$ scale). In Section 2.2 the theoretical standard deviation of $\log (\mathrm{SI})$ is $1.25 \phi_{L}(0.58)=0.72 \phi_{L}$. If $\phi_{L}=0.30$, then the standard deviation of a $\log (\mathrm{SI})$ is 0.216 . Since the $\operatorname{Pr}\left[\log (S I)<0.216 z_{p}\right]=p$, then for $p=0.001$,

$$
\begin{aligned}
& \operatorname{Pr}[\log (S I)<-3.1 * 0.216]=\operatorname{Pr}[\log (S I)<-0.67]=0.001 \\
& \text { i.e } \operatorname{Pr}[S I<0.51]=0.001
\end{aligned}
$$

The last item above may not be needed if it can be demonstrated that cell killing only occurs among individuals who are not sensitized to beryllium.

\subsection{Criteria To Determine If Internal Variability Is Too High}

The resistant estimate of the CV $\left(\tilde{\phi}_{L}\right)$ is too high if it exceeds a critical value CV*. The value of $\mathrm{CV}^{*}$ can be obtained using an empirical or theoretical approach. 


\subsubsection{Empirical Approach}

The empirical approach uses the distribution of $\phi_{L}$ estimates available from previous data (see e.g. Frome et al.[4] page 13 and page 26). This method could be applied to the control well counts on day 5 and day 7 (12 replicates per set). It could also be applied to the CV-mad estimates obtained from the Be stimulated wells (4 replicates per set).

\subsubsection{Theoretical Approach}

Assume that the $\log$ (base e) counts follow the Gaussian distribution with known $\phi$. Then use either mathematical analysis or simulation to determine a percentage point for the sampling distribution of $\tilde{\phi}_{L}$. Recall that $\phi$ is the standard deviation of the $\log$ of the counts, and corresponds to the $\mathrm{CV}$ on the original scale under the assumption that the standard deviation is proportional to the mean on the original scale (see ORNL-6818 Section 2.1).

\subsubsection{Mathematical Analysis}

This approach can be applied to the usual moment estimate of the standard of the $\log$ counts, i.e., NOT to the MAD estimate, $\tilde{\phi}_{L}$. If SD is the moment estimate of the standard deviation for a sample of size $n$ of $z$ (i)'s that are normally distributed with

known variance (i.e. $\phi^{2}$ ), then the chi-square distribution can be used to determine a critical value of the moment estimate of the standard deviation.

This should be a lower bound for the distribution of the resistant estimate $\tilde{\phi}_{L}$. For example, if $\phi=0.3$, then for control wells $(\mathrm{df}=11)$,

$\operatorname{pr}[\mathrm{SD}>0.401]$ is about 0.05 ,

$\operatorname{pr}[\mathrm{SD}>0.450]$ is about 0.01 ,

and, $\operatorname{pr}[\mathrm{SD}>0.506]$ is about 0.001 .

For the Be stimulated wells $(\mathrm{df}=3)$, and

and $\operatorname{pr}[\mathrm{SD}>0.48]$ is about 0.05 , and $\operatorname{pr}[\mathrm{SD}>0.70]$ is about 0.001 
The problem with this approach is that the distribution of $\tilde{\phi}_{L}$ will be more spread out than the distribution of the moment estimate of the standard deviation when the $\log$ counts follow the Gaussian distribution.

\subsubsection{Simulation Based Approach}

An alternative is to use simulation to generate the sampling distribution of SD and $\tilde{\phi}_{L}$. For a given value of $\phi$ generate say 10,000 samples of size $n(n=4,8$, or 12). Calculate the value of SD and $\tilde{\phi}_{L}$ for each sample and calculate the desired quantiles of the sampling distribution. In the absence of outliers this should match the results based on the chi-square distribution for $\mathrm{SD}$, but the null distribution of $\tilde{\phi}_{L}$ will be more spread out.

This same procedure can then be repeated with outliers being added, say ten percent of the time, to each of the samples of size $n$. This leads to a specified critical

value for $\tilde{\phi}_{L}$ that will depend on the value of $\phi$ that is used, and on the proportion of outliers that is assumed.

\section{Conclusions}

Three methods were described for identification of an abnormal blood LPT using LAV estimates of the SIs. These methods were applied to the BE-sample, Unacceptable, and Abnormal data sets. All three methods correctly identified the 32 known CBD cases as abnormal, and identified the seven known CBD cases in the BE-sample.

Results of applying the three methods to the BE-sample and Unacceptable data sets were presented. Table 5 summarizes the results for each method for the 20 NJC Unacceptable LPTs, gives the retest results and the evaluation of the patients' CBD status. Both Method 2 and Method 1A were effective at classifying beryllium sensitized individuals. Method $1 \mathrm{~A}$ had more results that were normal on retest by NJC using their usual criteria, i.e. the retest results were not based on Method 1A using LAV approach. Method 2 used the combined data from the NE (control) group and the BE worker group. Consequently, we cannot determine how this method would have classified the unacceptable LPTs in a "real time" situation, since the reference data base changes as new data becomes available.

Figure 4 suggests that there was "cell killing" present at the two highest Be con- 
centrations on Day 5 and 7 . Figure 5 and Figure 6 support the assumption that the $\log (\mathrm{SI}) \mathrm{s}$ are Gaussian in the center.

Distributions of resistant estimates $(\tilde{\phi})$ of the CV were presented-Figure 8 . These results show that the internal variability is similar for the BE-sample and NE-sample for control wells and treated wells on days 5 and 7 . These distributions are similar to those seen at ORISE and are centered at about $\tilde{\phi}=0.30$.

\section{Acknowledgments}

This research was supported by the Offices of Occupational Medicine, Environment, Safety and Health, U. S. Department of Energy under contract DE-AC05-96OR22464 with Lockheed Martin Energy Research Corp. The authors thank R. L Schmoyer, L. G. Littlefield, and S. P. Colyer for reviewing this report, and R. L. Neubert for technical assistance with data preparation.

The work has been authored by a contractor of the U.S. Government. Accordingly, the U.S. Government retains a nonexclusive, royalty-free license to publish or reproduce the published form of this work, or to allow others to do so for U. S. Government purposes.

\section{References}

[1] R.A. Armstrong, E.L. Frome, and D.S. Kung. A revised simplex algorithm for the absolute deviation curve fitting problem. Commun. Statist., B8:175-190, 1979.

[2] G. Basset, Jr. and R. Koenker. Asymptotic theory of least absolute error regression. Journal of the American Statistical Association, 73:618-622, 1978.

[3] J.M. Chambers, W.S. Cleveland, B. Kleiner, and P.A. Tukey. Graphical Methods for Data Analysis. Duxbury Press, Boston, 1983.

[4] E.L. Frome, M.H. Smith, L.G. Littlefield, R.L. Neubert, and S.P. Colyer. Statistical methods for the analysis of a screening test for chronic beryllium disease. Technical Report ORNL-6818, Oak Ridge National Laboratory, 1994.

[5] E.L. Frome, M.H. Smith, L.G. Littlefield, R.L. Neubert, and S.P. Colyer. Statistical methods for the blood beryllium lymphocyte proliferation test. Environmental Health Perspectives Supplement, 104:957-968, 1996.

[6] G. Li. Robust regression. In D.C Hoaglin, F. Mosteller, and J.W. Tukey, editors, Exploring Data Tables, Trends, and Shapes, chapter 8. John Wiley \& Sons, 1985. 
[7] P. McCullagh and J.A. Nelder. Generalized Linear Models. Chapman and Hall, London, 1989.

[8] R. McGill, J.W. Tukey, and W.A. Larsen. Variations of box plots. The American Statistician, 32:12-16, 1978.

[9] S.C. Narula. The minimum sum of absolute errors regression. Journal of Quality Technology, 19:37-45, 1987.

[10] C.R. Rao. Methodology based on the $\mathrm{L}_{1}$-Norm, in statistical inference. Sankhyā, $50: 289-313,1988$.

[11] R.M. Schrader and J.W. McKean. Small sample properties of least absolute errors analysis of variance. In Y. Dodge, editor, Statistical Data Analysis Based on the $L_{1}$-Norm and Related Methods, pages 307-321. Elsevier Science Publishers, NorthHolland, 1987.

[12] Statistical Sciences, Inc., Seattle. S-PLUS reference manual, 1991. 


\section{A. Detailed Report For LPT Data}

The following page describes the data from day 5 and day 7 for the LPT. All statistics in the top of the report are based on the outlier resistant approach described in Section 2.2. The results based on the method currently in use at NJC are listed at the bottom of the report.

The left hand side of the top panel describes the treatment groups and lists the observed well counts. Column 6 gives the fitted value obtained using the LAV method. Smad is computed using Equations 4 (see below). The residuals rounded to the the nearest logarithmic percent units $(L \%)$ are obtained as

$$
\operatorname{Residual}(L \%)=100 \times \frac{\text { count }}{\text { fit }}
$$

For example, day 5 control well $4: 100 * \log (231 / 252.4)=-9 \mathrm{~L} \%$.

The LAV estimates of the $\log (\mathrm{SI}) \mathrm{s}$ from Equations 3 and the corresponding SIs are listed in the second panel. Since this report was originally set up for ORISE data where positive controls are counted on day 5 , and NJC runs their positive controls on day 3 , we have not reported theses results. All LPTs in this report showed an adequate response to ConA and PHA

The estimates of the coefficient of variation $(\tilde{\phi})$ are listed near the middle of the page and were calculated as describe in Section A.2 of ORNL-6818. A separate estimate is calculated for the control wells and the treated wells on days 5 and 7 . These same numbers are listed in column 7 of the top panel in L\% units (i.e. they have been multiplied by 100). Pooled estimates are calculated for day 5 , day 7 , and overall. 


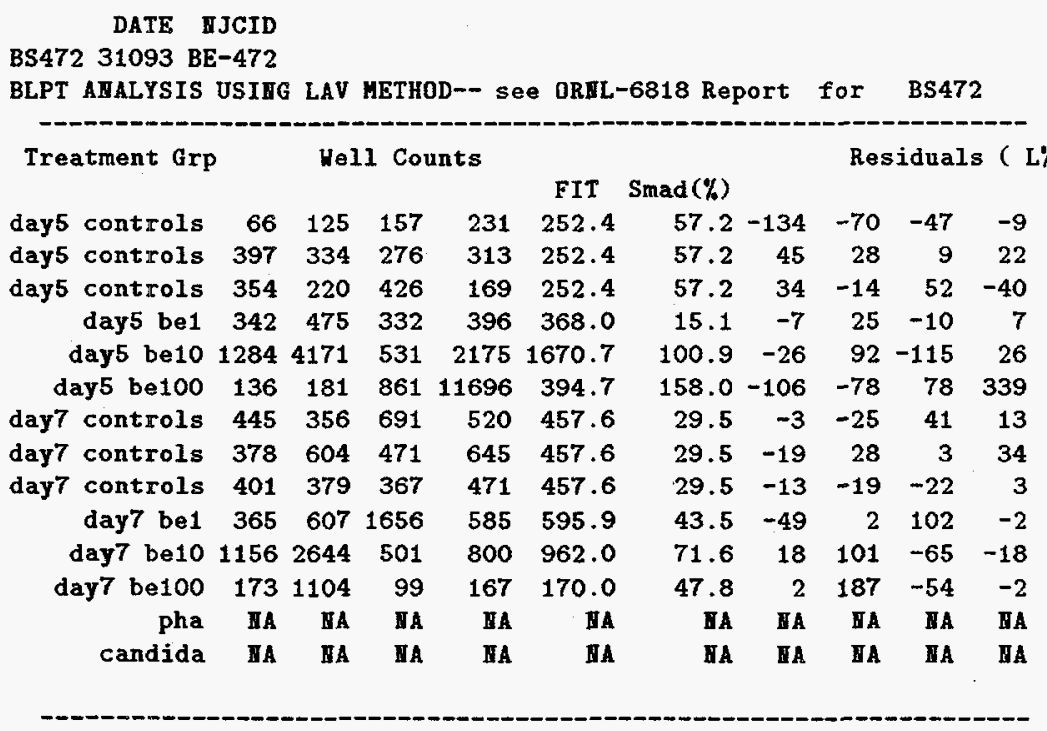

FIT $=$ Fitted Value $=\exp ($ median $)$ for each treatment group

Stimulation Indices

Day 5 Day 7 Positve Controls

be1 be10 be100 bel be10 be100 pha candida

$\begin{array}{lllllllllll}\log (\mathrm{SI}) & 0.377 & 1.890 & 0.447 & 0.264 & 0.742 & -0.991 & \text { BA } & \text { HA }\end{array}$

$\begin{array}{llllllllllll}\text { SI } & 1.457 & 6.618 & 1.563 & 1.302 & 2.101 & 0.371 & \text { VA } & \text { IIA }\end{array}$

Summary Statistics for BS472

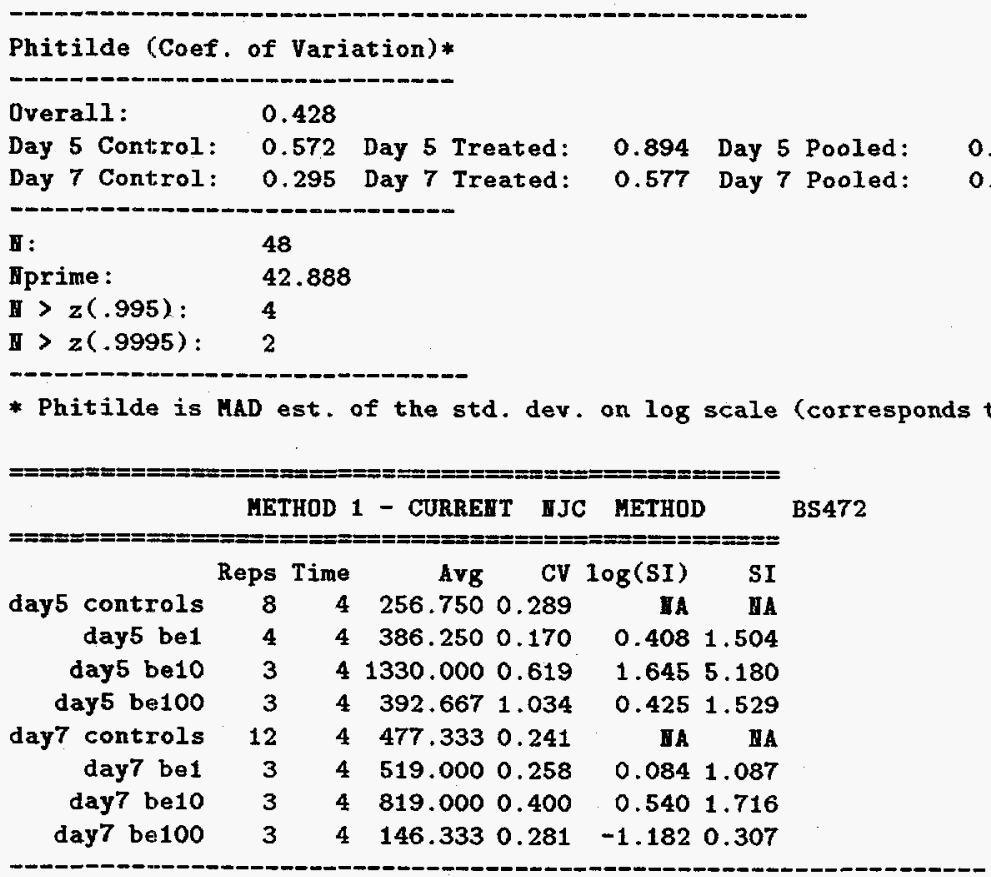


ORNL/TM-13338

\section{INTERNAL DISTRIBUTION}

1. D. E. Conrad

2. T. S. Darland

3. D. J. Downing

4-8. E. L. Frome

9. C. E. Oliver

10-14. S. A. Raby

15. D. E. Reichle

16. P. S. Rohwer
17-21. M. Leuze

22. R. F. Sincovec

23. Central Research Library

24. K-25 Applied Technology Library

25-26. Laboratory Records Dep.

27. Laboratory Records - RC

28. Patent Office

29. Y-12 Technical Library

\section{EXTERNAL DISTRIBUTION}

30. B. P. Barna, Cleveland Clinic Foundation, Immunopathology, One Clinic Center, 9500 Euclid Avenue, Cleveland, OH 44195-5131

31. D. L. Cragle, Medical Division, Oak Ridge Institute for Science and Education, P. O. Box 117, Oak Ridge, TN 37831

32. S. P. Colyer, Medical Division, Oak Ridge Institute for Science and Education, P. O. Box 117, Oak Ridge, TN 37831

33. G. R. Gebus, Occupational Medicine, EH-61, U. S. Department of Energy, 19901 Germantown Road, Germantown, MD 20874

34. R. Harbek, National Jewish Center for Immunology and Respiratory Medicine, 1400 Jackson Street, Denver, CO 80206

35. R. W. Hornung, National Institute for Occupational Safety and Health, 4676 Columbia Parkway, Cincinnati, OH 45226-1998

36. K. Kreiss, Division of Respiratory Disease Studies, National Institute for Occupational Safety and Health; 1095 Willowdale Rd, MS 234, Morgantown, WV $26505-2845$

37. L. G. Littlefield, Medical Division, Oak Ridge Institute for Science and Education, P. O. Box 117, Oak Ridge, TN 37831

38. T. Markham, Brush Wellman Inc., 1200 Hanna Building, Cleveland, OH 44115

39. F. Miller, Department of Pathlogy, SUNY Stony Brook, T-140, HSC, Stony Brook, New York 11794-8691

40. M. A. Montopoli, Occupational Medicine, EH-61 CC 270, U. S. Department of Energy, 19901 Germantown Road, Germantown, MD 20874

41. M. M. Mroz, OccupationalEnvironmental Medicine Division, National Jewish Center for Immunology and Respiratory Medicine, 1400 Jackson Street, Denver, CO 80206 
42. L. S. Newman, OccupationalEnvironmental Medicine Division, National Jewish Center for Immunology and Respiratory Medicine, 1400 Jackson Street, Denver, CO 80206

43. M. D. Rossman, Hospital of the University of Pennsylvania, 812 E. Gates Building, 3400 Spruce Street, Philadelphia, PA 19104

44. P. Seligman, Environmental Safety and Health, U. S. Department of Energy, 19901 Germantown Road, Germantown, MD 20874

45. Y. Shim,Epidemiology and Health Surveillance, EH-62 CC 270, U. S. Department of Energy, 19901 Germantown Road, Germantown, MD 20874

46. H. Stockwell,Epidemiology and Health Surveillance, EH-62 CC 270, U. S. Department of Energy, 19901 Germantown Road, Germantown, MD 20874

47. P. F. Wambach, Occupational Medicine, EH-61 CC 270, U. S. Department of Energy, 19901 Germantown Road, Germantown, MD 20874

48. Office of Assistant Manager for Energy Research and Development, DOE-ORO, P.O. Box 2008, Oak Ridge, TN 37831-6269

49-50. Office of Scientific and Technical Information, P.O. Box 62, Oak Ridge, TN 37830 